\title{
From global circulation to local flood loss: Coupling models across the scales
}

\author{
Guido Felder $^{\mathrm{a}, *}$, Juan José Gómez-Navarro ${ }^{\mathrm{b}}$, Andreas Paul Zischg ${ }^{\mathrm{a}}$, Christoph C. Raible ${ }^{\mathrm{c}}$, Veronika \\ Röthlisberger ${ }^{a}$, Denica Bozhinova ${ }^{c}$, Olivia Martius ${ }^{\mathrm{a}}$, Rolf Weingartner ${ }^{\mathrm{a}}$ \\ ${ }^{a}$ Institute of Geography \& Oeschger Centre for Climate Change Research \& Mobiliar Lab for Natural Risks, University of \\ Bern, Hallerstrasse 12, 3012 Bern, Switzerland \\ ${ }^{b}$ Department of Physics, University of Murcia, Facultad de Química, Campus de Espinardo, 30100 Murcia, Spain \\ ${ }^{c}$ Climate and Environmental Physics \& Oeschger Centre for Climate Change Research, University of Bern, Sidlerstrasse 5, \\ 3012 Bern, Switzerland
}

\begin{abstract}
Comprehensive flood risk modeling is crucial for understanding, assessing, and mitigating flood risk. Modeling extreme events is a well-established practice in the atmospheric and hydrological sciences and in the insurance industry. Several specialized models are used to research extreme events including atmospheric circulation models, hydrological models, hydrodynamic models, and damage and loss models. Although these model types are well established, and coupling two to three of these models has been successful, no assessment of a full and comprehensive model chain from the atmospheric to local scale flood loss models has been conducted. The present study introduces a model chain setup incorporating a GCM/RCM to model atmospheric processes, a hydrological model to estimate the catchment's runoff reaction to precipitation inputs, a hydrodynamic model to identify flood-affected areas, and a damage and loss model to estimate flood losses. Such coupling requires building interfaces between the individual models that are coherent in terms of spatial and temporal resolution and therefore calls for several pre- and post-processing steps for the individual models as well as for a computationally efficient strategy to identify and model extreme events. The results show that a coupled model chain allows for good representation of runoff for both longterm runoff characteristics and extreme events, provided a bias correction on precipitation input is applied. While the presented approach for deriving loss estimations for particular extreme events leads to reasonable results, two issues have been identified that need to be considered in further applications: (i) the identification of extreme events in long-term GCM simulations for downscaling and (ii) the representativeness of the vulnerability functions for local conditions.
\end{abstract}

Keywords: GCM, RCM, model coupling, downscaling, flood risk, flood loss

\footnotetext{
* Corresponding author

Email address: guido.felder@giub.unibe.ch (Guido Felder)
} 


\section{Introduction}

Floods are a natural hazard whose frequency is expected to rise in many areas due to ongoing anthropogenic climate change (IPCC, 2014). In addition, flood impacts are projected to increase due to increasing exposure (Bouwer, 2013, Hirabayashi et al., 2013, Kundzewicz et al., 2013). Since the occurrence of flood 5 events cannot be prevented, society has to take action to increase its resilience to these changing conditions. This requires planning adaptation strategies and realizing flood mitigation measures. Knowledge on potentially flood-affected areas is needed to reduce impacts of future flood events. This calls for greater understanding of possible meteorological scenarios, hydrological processes, flooding probability, and the vulnerability of the assets within flood affected areas.

A prominent approach to gaining insight into atmospheric processes, and therefore meteorological extremes leading to severe impacts, is based on numerical models. Using a modeling approach to identify potential flood-affected areas and the damages that could incur requires coupling several models to a model chain. The first element in such a model chain is a meteorological component that provides precipitation and temperature data, the key inputs for the rest of the model chain. These variables can be generated with stochastic weather generators. However, there are some known issues regarding the representation of extreme events, such as capturing the dependence between variables, and the dependence of variables in space (Furrer \& Katz, 2008, Semenov, 2008; Vandenberghe et al., 2010). Alternatively, the variables can be simulated in dynamical models by combining a Global Circulation Model (GCM) and a higher resolution Regional Climate Model (RCM). This is necessary when dealing with areas characterized by complex topography since the explicit simulation of topographically influenced processes leads to a more reliable simulation of extreme precipitation events (Keller et al., 2016).

The meteorological variables serve as input for a hydrological model, which simulates the runoff. The runoff can lead to flooding, which is simulated with hydrodynamic models. Eventually, a damage and loss model is used to estimate damages that result from simulated inundations. Although the individual parts of these modeling components are well established and commonly used in their respective research communities, a coupling of all these elements such as the one presented in this study has not been reported so far.

Coupling GCMs and RCMs to hydrological models has been the topic of numerous recent studies. In terms of spatial scales, such applications bridge calculations made for a global scale $\left(10^{4} \mathrm{~km}\right)$ to calculations made for the mesoscale $\left(10^{2} \mathrm{~km}\right)$. Most of these studies focused on a particular application of linked GCM and hydrological models. Several studies reviewed downscaling methods for hydrological applications (e.g. Fowler et al., 2007, Kundzewicz \& Stakhiv, 2010, Teng et al., 2012, Wilby, 2010). More recent studies focused on specific methodological problems in this procedure, namely on scale effects (Piniewski et al. 2013), rainfall statistics (Langousis et al., 2016), and hydro-meteorological extremes (Madsen et al. 2014. 
Tofiq \& Guven, 2014, Sunyer et al., 2015). The results of these studies have confirmed the applicability of linking GCMs to hydrological models via RCMs. Such model chains have been extensively used to assess climate change impacts on hydrological variables (e.g. Camici et al., 2014, Chen et al., 2013, Das et al., 2013, Fiseha et al., 2014, Kara et al., 2016, Li et al., 2014, Salathé et al., 2014, Xu et al., 2015).

Coupling a hydrological model with a hydrodynamic model has also been applied and evaluated in 40 numerous studies. This part of the model chain couples the mesoscale (1000 to $100 \mathrm{~km})$ to the micro-scale (1 $\mathrm{km}$ to $10 \mathrm{~m})$. Such coupled models have been assessed by Brandimarte \& Di Baldassarre (2012); Cook \& Merwade (2009); Lerat et al. (2012), and Kim et al. (2012), amongst others and have been extensively applied in studies that estimate flood wave propagation (e.g. Laganier et al., 2014), retention effects (e.g. Felder et al., 2017; Skublics et al., 2014, Vorogushyn et al., 2012), and flood probabilities (Altarejos-García et al., 2012, Dutta et al., 2013, Felder \& Weingartner, 2017).

Finally, hydrodynamic models have been coupled to loss models to estimate flood losses. This approach has been applied in several case studies where the input was mainly estimated using observed hydrographs rather than modeled ones (e.g. Apel et al., 2009, Cammerer et al., 2013, Ernst et al., 2010, Falter et al., 2015). The scale of the models depends mainly on the aim of the respective study, and it typically encompasses the micro-scale $(1-10 \mathrm{~m})$. A rough assessment of global flood risk using GCM and hydrodynamic models with relatively coarse resolution has been conducted in several studies (e.g. Winsemius et al., 2015). A recent study by Thieken et al. (2016) complements this approach with statistical downscaling to better represent local climate variables.

A review of studies in the recent literature is further summarized in Table 1. It is apparent how all parts of the end-to-end model chain have been covered by the literature. However, the coupling of all models that are needed for a deterministic local flood loss estimation using one single model chain has not been accomplished yet to our knowledge. Therefore, the aim of the present study is to assess the applicability, strengths, and weaknesses of a coupled model chain that covers all of the above-mentioned models. The first focus is on the general applicability of the model chain, i.e. what modeling strategy is feasible considering the available computational resources. The second question is whether such a model chain sufficiently represents physical processes. This is assessed in terms of long-term characteristics and in terms of extreme events. Third, the model chain is assessed regarding its applicability for spatial and temporal scales that range across various orders of magnitude. With this approach, new opportunities and constraints of model coupling across many scales can be evaluated, and sensitive interfaces between the models can be identified. This is important in order to develop a smooth transition of model variables across the scales and in terms of identifying technical constraints. The applicability test is conducted in view of the research question on identifying extreme precipitation scenarios in order to delineate their financial impacts (i.e. flood losses to buildings). 


\begin{tabular}{|c|c|c|c|c|c|}
\hline & GCM & RCM & $\begin{array}{l}\text { Hydrological } \\
\text { model }\end{array}$ & $\begin{array}{c}\text { Hydrodynamic } \\
\text { model }\end{array}$ & $\begin{array}{l}\text { Loss } \\
\text { model }\end{array}$ \\
\hline $\begin{array}{l}\text { characteristic spatial res. } \\
\text { characteristic temporal res. }\end{array}$ & $\begin{array}{c}10^{5} \mathrm{~m} \\
\text { day }\end{array}$ & $\begin{array}{c}10^{4} \mathrm{~m} \\
d a y\end{array}$ & $\begin{array}{l}10^{3} \mathrm{~m} \\
\text { hour }\end{array}$ & $\begin{array}{c}10 m \\
\text { second }\end{array}$ & $10 m$ \\
\hline Sunyer et al. (2015) & $\mathrm{x}$ & $\mathrm{x}$ & & & \\
\hline Langousis et al. (2016) & $\mathrm{x}$ & $\mathrm{x}$ & & & \\
\hline Fowler et al. (2007) & $\mathrm{x}$ & $\mathrm{x}$ & $\mathrm{x}$ & & \\
\hline Kundzewicz \& Stakhiv (2010) & $\mathrm{x}$ & $\mathrm{x}$ & $\mathrm{x}$ & & \\
\hline Wilby $(2010)$ & $\mathrm{x}$ & $\mathrm{x}$ & $\mathrm{x}$ & & \\
\hline Teng et al. (2012) & $\mathrm{x}$ & $\mathrm{x}$ & $\mathrm{x}$ & & \\
\hline Madsen et al. (2014) & $\mathrm{x}$ & $\mathrm{x}$ & $\mathrm{x}$ & & \\
\hline Tofiq \& Guven (2014) & $\mathrm{x}$ & $\mathrm{x}$ & $\mathrm{x}$ & & \\
\hline Camici et al. (2014) & $\mathrm{x}$ & $\mathrm{x}$ & $\mathrm{x}$ & & \\
\hline Piras et al. (2016) & $\mathrm{x}$ & $\mathrm{x}$ & $\mathrm{x}$ & & \\
\hline Duan et al. (2017) & & $\mathrm{x}$ & $\mathrm{x}$ & $\mathrm{x}$ & \\
\hline Cook \& Merwade (2009) & & & $\mathrm{x}$ & $\mathrm{x}$ & \\
\hline Di Baldassarre et al. (2010) & & & $\mathrm{x}$ & $\mathrm{x}$ & \\
\hline Kim et al. (2012) & & & $\mathrm{x}$ & $\mathrm{x}$ & \\
\hline Lerat et al. (2012) & & & $\mathrm{x}$ & $\mathrm{x}$ & \\
\hline Vorogushyn et al. (2012) & & & $\mathrm{x}$ & $\mathrm{x}$ & \\
\hline Laganier et al. (2014) & & & $\mathrm{x}$ & $\mathrm{x}$ & \\
\hline Skublics et al. (2014) & & & $\mathrm{x}$ & $\mathrm{x}$ & \\
\hline Altarejos-García et al. (2012) & & & $\mathrm{x}$ & $\mathrm{x}$ & \\
\hline Falter et al. (2015) & & & $\mathrm{x}$ & $\mathrm{x}$ & $\mathrm{x}$ \\
\hline Thieken et al. (2016) & $\mathrm{x}$ & & $\mathrm{x}$ & $\mathrm{x}$ & $\mathrm{x}$ \\
\hline Apel et al. (2009) & & & & $\mathrm{x}$ & $\mathrm{x}$ \\
\hline Ernst et al. (2010) & & & & $\mathrm{x}$ & $\mathrm{x}$ \\
\hline Cammerer et al. (2013) & & & & $\mathrm{x}$ & $\mathrm{x}$ \\
\hline Winsemius et al. (2015) & & & & $\mathrm{x}$ & $\mathrm{x}$ \\
\hline Current study & $\mathbf{x}$ & $\mathbf{x}$ & $\mathbf{x}$ & $\mathbf{x}$ & $\mathbf{x}$ \\
\hline
\end{tabular}

Table 1: Model types and their characteristic spatial resolution and a non-exhaustive overview of studies in which coupled models have been applied. The characteristic resolution is understood as a rough statement on the magnitude and differs from model to model. Studies that remarkably differ from these characteristic resolutions, e.g. flood risk assessments on a global scale, are not considered. 


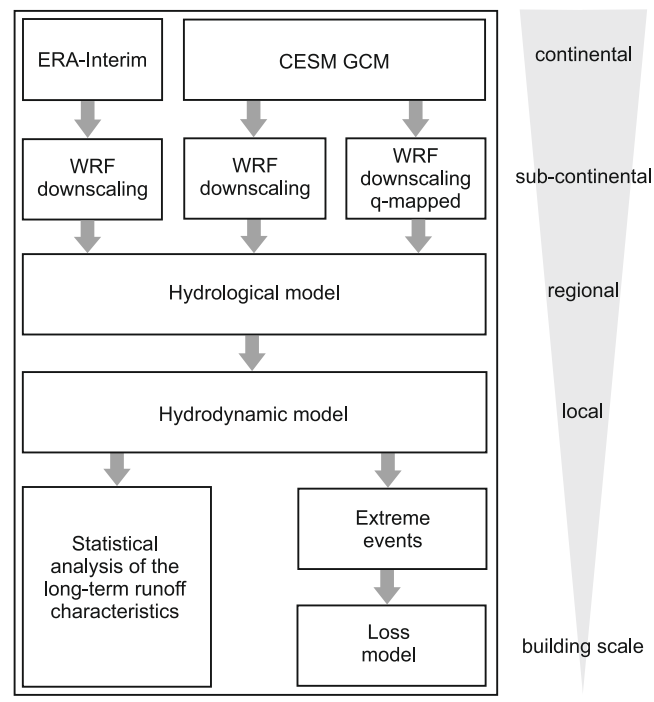

Figure 1: Chain of coupled models used in this study. The process representations range from hundreds of kilometers (top) to a few meters (bottom). On the right, the characteristic scale of the process representation is indicated.

\section{Description of the model chain}

The approach followed in this study entails selecting extreme events within a long climate simulation, applying the full model chain to such cases, and comparing the results with recent events, with the aim of gaining insight into physically plausible extreme precipitation scenarios over a time frame beyond the short instrumental record. Compared to resampling approaches or the use of stochastic weather generators, the main advantage of the proposed approach is that it is less dependent on the period and the quality of the instrumental record.

The study design is shown schematically in Fig. 1 . The meteorological inputs into the model chain are the results of three different modeling approaches: dynamical downscaling based on ERA-Interim reanalysis, dynamical downscaling based on a GCM, and the latter followed by a statistical bias correction. These three precipitation modeling approaches are used separately for the model assessment. First, the model chain is calibrated and validated using input from ERA-interim. This enables an assessment of the model chain's ability to represent the natural system. In a second step, the precipitation modeled by a downscaled free GCM run is used as input both in an uncorrected and in a quantile-mapped mode. A comparison with observed precipitation and runoff data allows for an assessment of the model chain regarding longterm system behavior. It is assumed that if the model is able to represent the long-term characteristics of hydrological variables, it is also applicable for extreme events. As a showcase, the model is driven by a set of downscaled and bias corrected extreme events. For this particular purpose, a number of candidates to precipitation events within a 400-year GCM simulation are downscaled and fed into the model chain. This enables the assessment of the model chain when it comes to extreme events and losses. 


\subsection{Climate modeling}

The input required by the hydrological component of the model chain is the precipitation flux, as well as the temperature. These variables are produced in our study using two different RCM simulations, the first driven by a GCM and the second by a reanalysis product. The resolution of the final downscaled fields is $2 \mathrm{~km}$ in both cases.

\subsubsection{Reanalysis}

ERA-Interim is a reanalysis product from the European Centre for Medium Range Weather Forecast. It is produced running the IFS model at a spectral resolution of T255 and 60 vertical levels (Dee et al. 2011). The setup includes a number of observational datasets that are assimilated in the model with a 4-D variational analysis. This dataset covers the period from 1979 up to the present day. To drive the RCM, a selection of this data spanning 1979-2013 with a 6-hour temporal resolution was used. The highest spatial resolution was used, with data interpolated to $0.75^{\circ} \times 0.75^{\circ}$.

\subsection{2. $G C M$}

The GCM data used in this study consist of a simulation carried out with the first version of the Community Earth System Model (CESM, Hurrell et al., 2013). The model is a fully coupled GCM considering components of the atmosphere, land, sea ice, ocean, and the carbon cycle. The model is run with a horizontal resolution of about $1^{\circ}$ for all components.

Two different simulations were performed in the process. First, a so-called control simulation, where forcings are kept constant to $850 \mathrm{AD}$ conditions, was run for 500 years. Only the last 400 years are used in this study to identify extreme precipitation events (see details in the following section). Second, the latter simulation was branched from a preindustrial (1850 AD) simulation provided by the NCAR and continued until 2005. Details on the forcing used and a description of the simulated climate is given in Lehner et al. (2015). Note, however, that from the latter simulation only the period 1986 to 2005 is used in this study to deduce the bias correction of the GCM-RCM part of the chain.

\subsection{3. $R C M$}

The RCM is version 3.5 of the Weather Research and Forecasting Model (WRF) (Skamarock et al., 2008). This is a limited area model that solves the non-hydrostatic equations of atmospheric dynamics over a terrain-following coordinate system. It is a state-of-the-art RCM that is customarily used for both meteorological and climate purposes (García-Valdecasas Ojeda et al., 2017; Gómez-Navarro et al., 2015 , Stucki et al., 2016; Messmer et al., 2017, among others). The model setup employed in this study is nearly the same as that described by Gómez-Navarro et al. (2015), and implements four nested domains that downscale the large-scale driving data from either ERA-Interim or CESM to $2 \mathrm{~km}$ in its innermost domain 
(Fig. 2). More recently, Gómez-Navarro et al. (2018) performed a validation of this model configuration regarding its ability to simulate the precipitation regimes over Switzerland. The high resolution in its innermost domain has been selected as it minimises the scale gap in the coupling with the next model chain, therefore minimising systematic errors. Further, it enables the explicit simulation of convective processes,

increased performance of simulations with such high-resolution (e.g. Ban et al., 2014, Keller et al., 2016, Zittis et al. 2017). Prein et al. (2015) reviewed the recent bibliography about convection permitting simulations. They report how the added value of this type of simulations is especially notable at sub-daily scale and in summer. This makes this setup especially suitable for reproducing summer extreme events in areas of complex orography, precisely the phenomena most relevant for the area of interest of this study. Further, this high resolution facilitates the explicit simulation of the physical links between the large-scale circulation, the mesoscale processes responsible for regional patterns of precipitation, and eventually the discharge processes, which is the main purpose of the proposed model chain. Such high-resolution has the drawback of a huge computational cost that precludes the downscaling of the entire 400-year period, therefore the emphasis in case studies emerges as an alternative.

The only difference between the model configuration in the simulations driven by ERA-Interim (hereafter WRF-ERA) and those driven by CESM (hereafter WRF-CESM) is that in the latter no nudging scheme is employed, whereas in the former horizontal wind, temperature, and humidity are nudged above the boundary layer. The rationale behind this procedure is that the GCM should not be regarded as accurately as the reanalysis product, especially accounting for the overestimation of zonal circulation (Bracegirdle et al. 2013) and other biases reported for this particular model setup (Lehner et al., 2015).

Thus, in total, three different sets of RCM simulations are used in this study - one continuous run driven by ERA-Interim in the period of 1979-2013 using nudging, a second continuous run driven by CESM for the period of 1986-2005, which is used for the bias correction, and finally a set of short runs around extreme cases which are selected from a long 400-year CESM run according to the criteria detailed in Section 3.3. Temperature data were directly derived from the model output without further processing, after confirming that there is no systematic bias (shown in Fig. 5).

\subsection{Hydrological and hydrodynamic modeling}

The deterministic, semi-distributed hydrological model PREVAH (Viviroli et al., 2009b) was applied for the hydrological modeling component. Various studies in areas similar to the present study area confirm the applicability of the model, particularly for modeling extreme events (Felder \& Weingartner, 2017, FOEN, 2009: Orth et al. 2015, Viviroli et al., 2009a; Zappa et al., 2015). The model uses hydrological response units (HRU's) that are directly routed to the catchment outlet. For the present case, the HRU's are built based on catchment characteristics (altitude zone, slope, aspect, land use, soil type and glaciation) at a $2 \mathrm{~km}$ 


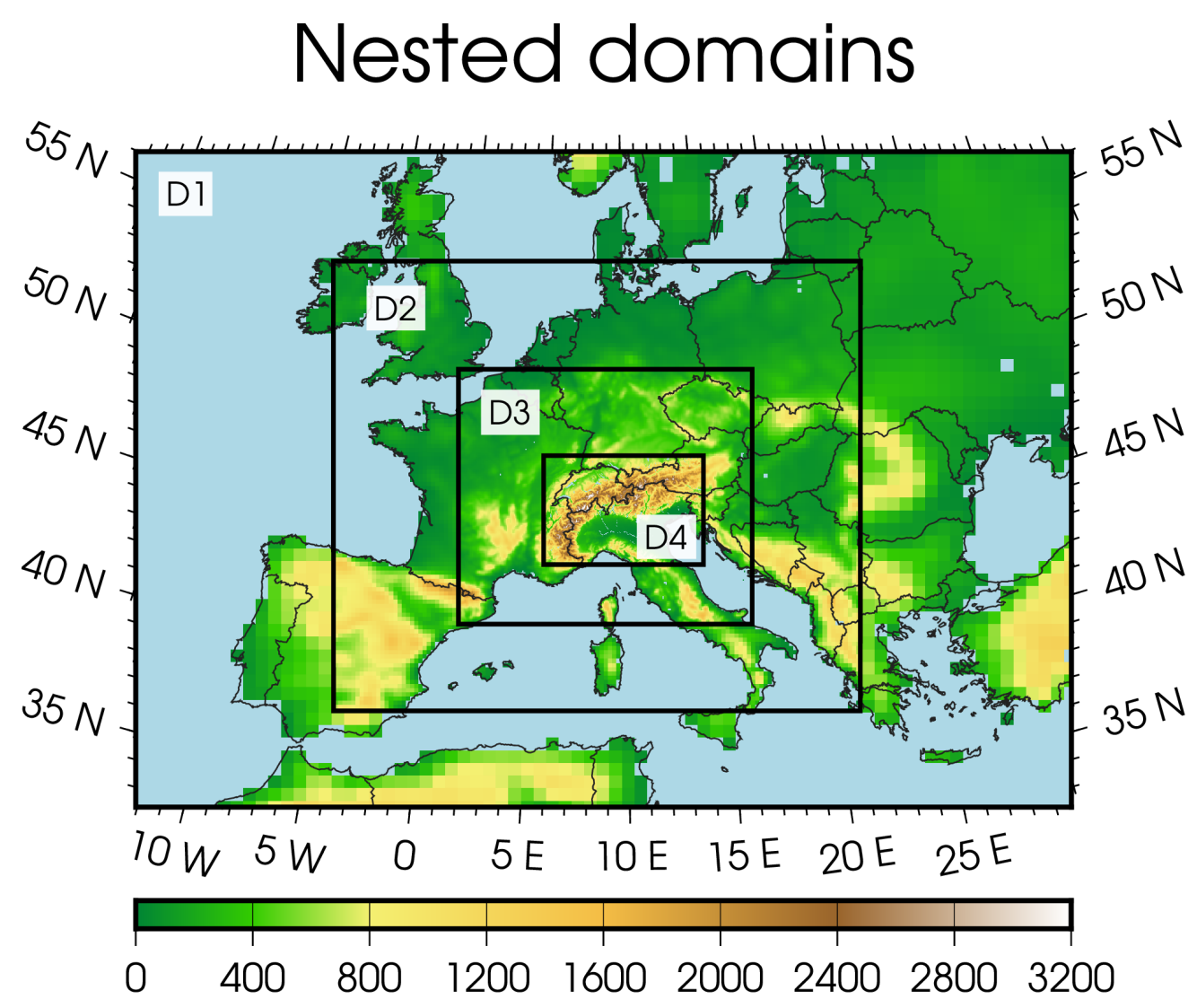

Figure 2: Configuration of the four two-way nested domains. The spatial resolutions are $54,18,6$, and $2 \mathrm{~km}$, for domains D1 to D4, respectively. The figure depicts the orography and land sea mask implemented in the simulations. 
resolution. Twelve parameters are calibrated (14 in case of glaciated catchments). Fourteen sub-catchments with an average area of $200 \mathrm{~km}^{2}$ were independently modeled; their location is shown in Fig. 3 . For 9 out of these 14 sub-catchments calibration was performed using hourly resolved discharge data, leading to NSE skill-scores between 0.70 and 0.92 . The other 5 sub-catchments were parametrized using the regionalization approach proposed by Viviroli et al. (2009a).

The outflow from the sub-catchments has to be routed through the floodplains towards the river basin outlet. The output of the hydrological model is fed into the hydrodynamic model as the upper boundary condition or as lateral inflow. In this study, the 1D hydrodynamic model BASEMENT (Vetsch et al., 2016) was used, which is based on the continuity equation and solves the Saint-Venant equations for unsteady onedimensional flow. The model structure and its mathematical foundations are described in detail by Vetsch et al. (2016). BASEMENT simulates water fluxes through floodplains with their topography represented by cross-sections. For each time step and cross-section, the model computes flow velocity and water surface elevation. The hydrodynamic model is set up to incorporate all significant flood-prone areas and potential retention areas in the main river valley. Riverbed cross-sections were provided by the Swiss Federal Office of Environment (FOEN). These cross-sections are expanded to the whole valley ground based on a $0.5 \mathrm{~m}$ laser scan digital elevation model. This procedure enables the effects of widespread inundation and retention processes on discharge routing to be captured (Cook \& Merwade, 2009, Mejia \& Reed, 2011). A cross section spacing of $150 \mathrm{~m}$ and a perpendicular orientation is chosen based on recommendations made by Ali et al. (2015), Castellarin et al. (2009), and Samuels (1990). With this, the lake regulation and the retention effects of the lakes and the floodplains are considered.

The hydrodynamic model is calibrated on observed data. The calibration is based on an adjustment of the roughness (Strickler) coefficients $\left(k_{\text {str }}\right)$ of the single cross-sections. Separate values are set for the riverbed, the adjacent levees, and the hinterland, aiming to reconstruct observed propagation times and peak flows. The roughness parameters are calibrated by representing the stage-discharge curves of all available river gauging stations in the study area. These coefficients are transferred to the neighboring cross-sections. The behavior of the lake outflows is described using the Poleni equation, whereas the dimensionless factor $\mu$ is empirically adjusted in order to reconstruct observed flood events. A more detailed description of the applied hydrological and hydrodynamic model as well as a comprehensive explanation of the calibration strategy is provided in Felder et al. (2017). The model validation on observed flood events shows an error of $\pm 2 \mathrm{~cm}$ in terms of water level (mean flow depth: $2 \mathrm{~m}$ ) or $\pm 5 \mathrm{~m}^{3} \mathrm{~s}^{-1}$ in terms of discharge (mean runoff: $\left.122 \mathrm{~m}^{3} \mathrm{~s}^{-1}\right)$. The model coupling with the hydrological model is external, which means that there is no direct interaction between the models and backwater effects are only treated within the spatial domain of the hydrodynamic model. 


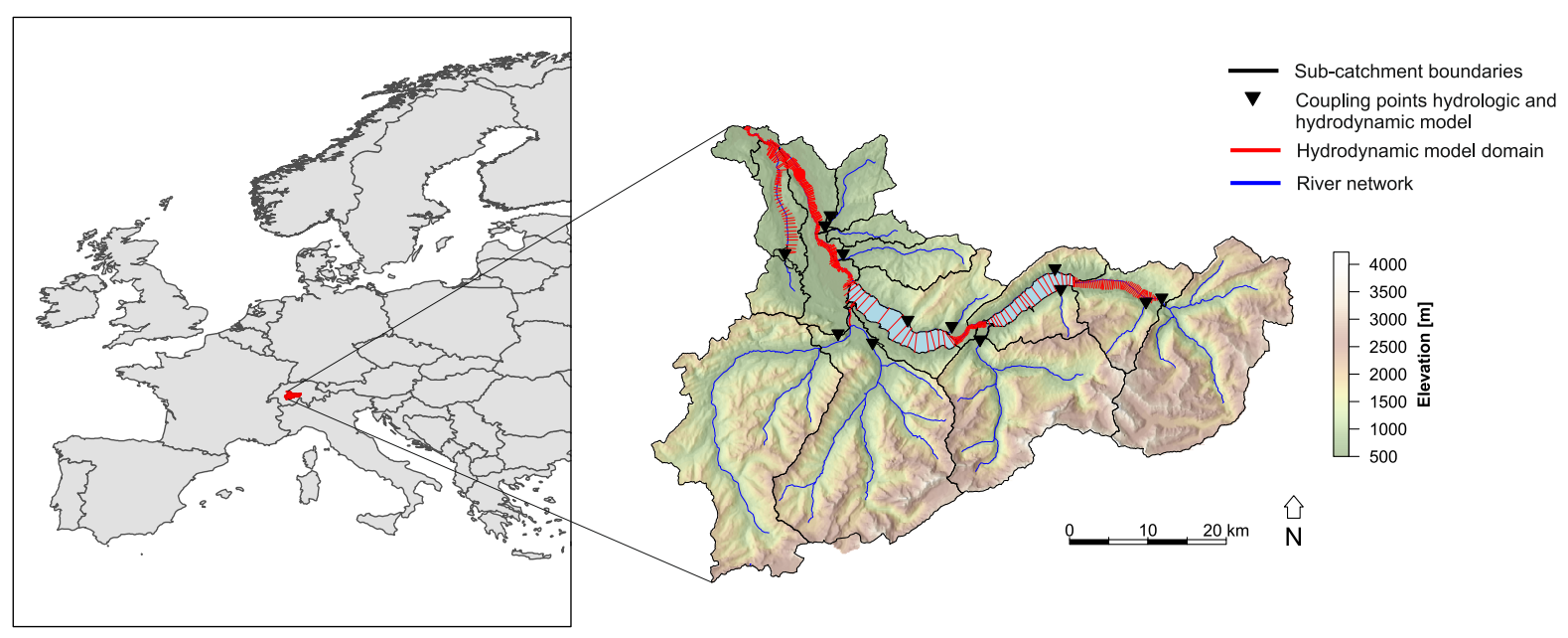

Figure 3: Study area and sub-catchments

\subsection{Loss modeling}

A flood loss model is nested into the 1D hydrodynamic model and consists of a 2D flood inundation model for each floodplain, a building dataset, and a set of vulnerability functions. The flood loss model computes losses to buildings (structural damages). Fatalities, damages to infrastructure or house content, and indirect damages due to business interruption are not considered in this study.

Flood dynamics in the floodplains are modeled with the 2D inundation model LISFLOOD-FP $\overline{B a t e s}$ \& de Roo 2000). This two-dimensional hydrodynamic model is designed to simulate dynamic flooding in complex terrains in a computationally efficient way. The model computes water depths for each grid cell and time step. In this study, the model was set up with a spatial resolution of $50 \mathrm{~m}$. The digital terrain model (DTM) is upscaled from a Lidar DTM with a high spatial resolution $(0.5 \mathrm{~m})$. The channel flow is computed in a subgrid mode (Neal et al. 2012). This subgrid channel module requires information on the heights of the river bed and of the lateral levees, on the river width, and on the shape of the river bed. These data are computed at high resolution and aggregated onto the target resolution by conserving the cross-sectional area of the river channel from the high-resolution terrain model. The 2D hydrodynamic model is calibrated in terms of reproducing the stage-discharge relationships at the gauging stations at bank-full discharge and the known channel capacity along the river reaches. As in the 1D hydrodynamic model, the roughness coefficients calibrated at the river gauging stations are transferred to the remaining river reaches. The model is validated on the basis of documented flooding. The fit of the inundation model (Bates \& de Roo, 2000) computed on the basis of observed discharges of the flood event in August 2005 and a comparison between modeled and observed inundation extents ranges between 0.5 and 0.9 , depending on the river reach. The lower values can be explained by dam breaks that occurred in reality but are not considered in the model. 
The 1D hydrodynamic model provides the boundary conditions (primary and lateral inflows and lake levels) for the 2D inundation model. Hence, the 2D inundation model is nested into the 1D hydrodynamic model. The 2D inundation model provides the flow depths during floods in the floodplains as the input for the loss computation module. The loss module consists of a dataset of buildings, each object classified by type, functionality, volume, reconstruction costs, and number of residents (Röthlisberger et al., 2017). The building footprints were provided by the Federal Office for Topography Swisstopo. The volume of the buildings is derived from LIDAR data provided by the Canton of Bern. The monetary values of the buildings (reconstruction costs) are calculated based on the above-ground building volume by means of a heuristic determination of mean values for reconstruction costs per cubic meter (regional construction costs according to SVKG (2012)). In addition, the number of residents is attributed to each building using the residential statistics of the Federal Office for Statistics.

The flow depths resulting from a model simulation were attributed to each building and provide the basis for estimating an object-specific degree of loss. The degree of loss is the ratio between the loss and the total reconstruction cost of the building. It depends on the flow depth and is used to compute the damage to the building by multiplying it with the reconstruction value of the building. The relationship between the degree of loss and the flow depth is described by an empirically derived vulnerability function. A vulnerability function is needed to determine losses based on the flow depths according to the characteristics of the individual buildings. Currently, no specific vulnerability function is available for Switzerland, and there is no dataset available to validate the flood loss module due to data privacy regulations in the study area. Hence, a selection of different flood vulnerability functions was applied to consider the uncertainties in the flood loss estimation and to capture a range of possible outcomes in the flood loss estimations. For the present study, vulnerability functions suggested by Dutta et al. (2003), Hydrotec (2001), Papathoma-Köhle et al. (2015), and Totschnig et al. (2011) are used in the flood loss computation module. In summary, the flood loss module in this model chain computes the damages on the single-building scale and aggregates the losses to the basin scale for each model simulation.

\section{Data and methods}

\subsection{Study area and data availability}

The study was conducted for the catchment of the Aare River up to Bern (see Fig. 3). The catchment is located at the northern edge of the Swiss alps and covers about $3000 \mathrm{~km}^{2}$. The catchment's elevation ranges from 500 to $4200 \mathrm{~m}$ a.s.l., with a mean elevation of $1600 \mathrm{~m}$ a.s.l. The southern part of the catchment consists of alpine mountains. Several alpine peaks within this area exceed $4000 \mathrm{~m}$ a.s.l., and parts of it are glaciated $(8 \%$ of the total catchment area). The northern part of the catchment consists of a relatively flat valley, where widespread potential floodplains are present. Two natural but artificially managed lakes are 
located between the northern and the southern part of the catchment. The alpine (southern) part of the catchment can roughly be subdivided into four major sub-catchments that each cover approximately 500 $\mathrm{km}^{2}$ and drain into one of the lakes. The lakes have a balancing effect since they dampen peak discharges and attenuate low flow situations. The alpine sub-catchments determine the regime of the whole study area, which is driven by glacier- and snow melt, with high flows in summer and low flows in winter. The northern sub-catchments cover about $500 \mathrm{~km}^{2}$ in total; their outflow is mainly driven by rainfall. Since they directly contribute to the catchments runoff without draining into a lake, they can significantly influence 400-year control run conducted with CESM.

The proposed method is based on the assumption that the precipitation simulated by the GCM is related to the one obtained in the RCM. Thus, the precipitation averaged over a region that encompasses Switzerland (12 grid points in the GCM) is evaluated. A set of grid points is used in order to avoid misinterpretations, the peak discharge of the catchment. The typical response time of the whole catchment amounts to 1-2 days. The complex physiographic setup of the catchment bears considerable consequences for atmospheric modeling as the complex topographic structure is not captured by the spatial resolution in the CESM. This drawback justifies the necessity of dynamically downscaling the GCM in order to produce physically realistic meteorological fields suitable for this complex catchment. Further, the presence of lakes and widespread potential floodplains calls for a hydrodynamic model that is able to capture retention and inundation effects on discharge behavior.

\subsection{Observational dataset}

Discharge time series in a 10 min temporal resolution covering at least 30 years were available for nine sub-catchments, as well as for the catchment outflow. Data were provided by the Swiss Federal Office of Environment. The discharge time series of the sub-catchments are used for the calibration and validation of the hydrological model. The discharge time series gauged at the catchment outflow is used for the calibration of the hydrodynamic model, as well as for the validation of the coupled hydrologic-hydrodynamic model.

To validate the simulated precipitation and to carry out a bias correction, a gridded observational dataset is used. It consists of the RhiresD dataset, provided by MeteoSwiss (MeteoSwiss, 2015). This observational dataset, hereafter referred as OBS, is based on daily precipitation sums measured by the MeteoSwiss highresolution rain-gauge network. The dataset is provided on a $2 \mathrm{~km}$ resolution, and has been spatially matched onto the $2 \mathrm{~km}$ grid of the WRF simulation's innermost domain.

\subsection{Selection of extreme cases}

Although the aim of this study relies on showing the feasibility of the full model chain, we showcase it with an application in the simulation of meteorological extreme events. Such events are selected within the as the GCM uses subgrid parametrizations (in particular for precipitation) that could lead to artifacts at 
single grid points nearby or above topography. Out of this time series, the most extreme cases are selected according to the following selection procedure:

- The selection is carried out separately and for each season independently.

- The daily precipitation series are aggregated in running windows of variable length $(1,2,3,5$ and 10 days). The resulting series are considered independently.

- The series corresponding to each window are inspected, and the 4 single most extreme events for each temporal frame are selected.

Note that this algorithm does not explicitly exclude days where precipitation leads to multiple events, i.e. the precipitation which occurred on the most extreme day may also have contributed to a 2-day extreme event, etc. All in all, the selection comprises $5 \times 4 \times 4=80$ events that require the simulation of $4 \times 4 \times(1+2+3+5+10)=336$ days. Thus, the selected number of events leads to a feasible number of days to be downscaled with the RCM with the available computational resources. Also, the use of various temporal windows accounts for the fact that some extreme floods are not always produced by one heavy, isolated precipitation event, but are rather caused by precipitation accumulation over several days. Furthermore, selecting extremes separately by season aims to minimize problems due to seasonality improperly reproduced by the GCM. That is, extremes in all seasons are studied, regardless of when, across the annual cycle, the GCM produces the strongest precipitation.

It can be argued that these events might not necessarily correspond to extreme episodes in the real, externally forced climate. To demonstrate that this is not a bottleneck for this selection, the control simulation has been compared to a transient simulation for the 1000-2010 period (Lehner et al., 2015) in terms of extreme precipitation over Switzerland. Both simulations were carried out with the same CESM configuration. The results (not shown) indicate that the severity of extreme events is hardly distinguishable between control and transient simulations, and that the severity of these episodes remains stationary during the last millennium. Therefore, the extreme events within the control simulation are a sensible surrogate for the ones that can be expected in more realistic externally forced simulations. In any case, these cases are selected to serve as test bed for the model chain, and its value resides in its intrinsic physical consistency. Therefore, the interpretation of what type of events they represent is a consideration that does not affect the generality of the results regarding the model chain that is presented hereafter.

\subsection{Bias correction of precipitation}

The data produced by the GCM are not as accurate as those produced by reanalysis products (Wang et al. 2014). A prominent, well known bias is the overestimation of zonal circulation over Europe (e.g., Bracegirdle et al., 2013). These biases are introduced in the RCM through the domain boundaries, and 
they induce systematic biases in the precipitation flux simulated in the innermost domain of the RCM. In addition, the RCM itself is a source of errors and uncertainties arising both from the parametrization of certain sub-grid processes and from a limited understanding of some components of the climate system. It is important to acknowledge and assess systematic biases, although they are to some extent inherent in all areas of climate modeling. A comprehensive analysis of the model performance in both the WRF-CESM and WRF-ERA simulations is presented in Gómez-Navarro et al. (2018). They identify biases in WRF-CESM associated to wrong seasonality in the driving model, which leads to an underestimation (overestimation) of precipitation in summer (winter). Such biases play a key role in this study, as the hydrological processes simulated in the following steps of the model chain exhibit non-linear behavior that makes them very sensitive to small deviations in precipitation fluxes. Therefore, some relevant results regarding the ability of the RCM to simulate observed climate are presented. These are relevant for the discussion of the outcome of the rest of the model chain.

As a mean to compensate for systematic biases in the output of the RCM, a bias correction technique was applied, generating adjusted precipitation fluxes that are in principle more representative of the observed precipitation rates than those in the raw RCM output. This so-called Quantile Mapping (QM) technique (Gudmundsson et al. 2012, Jakob Themeßl et al., 2011) calibrates a non-parametric statistical model that can be used to adjust the simulated events, with the underlying assumption being that the biases found during the calibration period are consistent across different time periods and even during unobserved extreme events. In a nutshell, bias correction is based on using a climate simulation and an observational product to obtain the sampling quantiles of both datasets independently. Then, this information is used to map the daily simulated precipitation onto the distribution of observed precipitation (Jakob Themeßl et al., 2011).

This simple method ensures that the sampling distribution of the corrected values mimics the one in the observations. Thereby, not only the mean and variance but also higher-level moments of the distribution are reproduced. It relies however on two important assumptions. The first assumption is that the corrected dataset inherits the properties of the observational product, which is considered a perfect surrogate of actual precipitation. Second, the sampling distributions of quantiles in the simulation and observations is assumed to be an accurate estimation of the actual, unknown, distributions, which is closely related to the length of the period used. This transient 20-year simulation spans the period of 1986-2005 with exactly the same configuration as the one used to simulate the extreme events. Clearly, some extreme cases exceed the precipitation range covered by the 20-year simulation, so extrapolation becomes necessary. The underlying assumption is that the bias in percentiles beyond $95 \%$ is constant, which is equivalent to assuming a straight line of slope 1 in a quantile-quantile diagram.

The use of QM needs to be accompanied by a word of caution. Post-processing techniques are in the focus of recent and intense debate (Maraun, 2016). As described above, QM establishes a relationship between two probability distributions. Therefore, a choice must be made regarding the data to be used to calculate 
such distributions, e.g. the precipitation in each grid point or the precipitation average in a certain area of interest. Using either of these data, QM (and more generally every bias-correction technique) has the effect of a statistical downscaling, which breaks down the physical consistency of the model. This is the case when the spatial structure of the simulated field is disturbed due to the different corrections carried out in different grids. To minimize this side effect, a less aggressive correction is applied, namely using the single couple of distributions obtained from the daily precipitation averaged over the Aare catchment in both the WRF -CESM and in OBS for the period 1985-2005. Then, both distributions are used to correct each grid cell independently. The use of just one general transformation is meant to minimize the risk of statistical over-fitting, which might disturb the intended physical consistency with the RCM. Furthermore, it should be considered that although this procedure ensures that the correction is accurate across all distribution moments in the area used to establish the distributions, it may lead to worse corrections when it is applied in areas away from it, as shown in the following sections. This effect implies that the correction is especially suited for the Aare catchment, although it may lead to erroneous corrections in other areas that are not considered in the rest of the model chain. Finally, note that QM is applied in this study twice, first for the continuous 1985-2005 run and then for the selected events. Daily PDFs are used to correct daily series of precipitation in the former case, in which all days without a minimum threshold are considered. However, to correct the selected events the PDFs are obtained for the precipitation aggregated over the corresponding temporal windows, e.g. 5-day events are corrected according to the PDFs obtained for precipitation in chunks of 5 days.

\subsection{Initial conditions for the hydrological and the hydrodynamic model}

As explained in Section 3.3, the number of days that can be downscaled is limited due to limited computational resources. Such event-based modeling is based on several assumptions on the initial catchment conditions. The initial state of the hydrological model was set to average seasonal conditions in terms of storage levels, soil moisture, and snow-water-equivalent. Therefore, four sets of initial conditions were defined. The same procedure was applied to define the initial conditions of the 1D hydrodynamic model, namely the initial lake levels and the tributary inflows. The model was run for a period of 12 days. Therefore, at least 2 days after the precipitation event were modeled as well (exact number depends on the length of the scenario). This ensures that no peak discharges are missed, even when they occur after the actual precipitation event.

\section{Results}

First, an evaluation of the model chain regarding long-term runoff characteristics is presented, since acceptable model performance on a long-term basis is required for a reliable assessment of extreme event 
characterization. Then, the evaluation focuses on the modeling and reconstruction of extreme events, which is of particular importance for further applications of similar model chains for flood loss modeling.

\subsection{Long-term characteristics of precipitation simulation}

Precipitation biases in the WRF-CESM simulation illustrate how the bias correction procedure applied on a daily basis to the full simulated period (Section 3.4 adjusts the precipitation values over the Aare catchment. Fig. 4 illustrates the systematic biases present in the WRF-CESM simulation showing the maps of accumulated precipitation for each season in the observations (top), the raw WRF-CESM simulation (middle), and the bias-corrected one (bottom). A comprehensive discussion of these biases, as well as a comparison with biases of the WRF-CESM and WRF-ERA simulations and deficiencies in the simulation of the large-scale circulation within CESM, is provided by Gómez-Navarro et al. (2018). Fig. 4 demonstrates how WRF systematically overestimates winter and spring precipitation, while it underestimates summer precipitation. The deviations of the modeled precipitation amounts from the observed ones are not constant over the different seasons. This calls for studying extreme events independently for each season. These biases can be removed to a great extent applying QM, as depicted in the bottom row. The deficiencies regarding the annual precipitation cycle are apparent in Fig. 5 , where the precipitation averaged over the Aare catchment for each month is shown for the simulation as well as for the output of the QM correction. Clearly, the bias correction adjusts the representation of the annual cycle, increasing (decreasing) their values in the warm (cold) seasons and narrowing differences with the observations. The bold lines represent the monthly mean temperature derived from the WRF-ERA simulation and from the observed dataset. They confirm that the seasonal pattern of the mean temperature is well represented by the WRF-ERA simulation, which is important for a reliable modeling of snow accumulation or snow melt.

The overall performance of the three precipitation products under consideration is further shown in Fig. 6, where the quantiles of the modeled 1-day areal mean precipitation intensities are compared to the quantiles of the observed mean areal precipitation. The areal mean precipitation based on the downscaled reanalysis data is congruent with the observed quantiles in low-intensity cases. However, it systematically overestimates the observed quantiles above an intensity of $20 \mathrm{~mm}$, and particularly above $60 \mathrm{~mm}$. This means that mean areal precipitation derived from this dataset is systematically too high in the upper range of quantiles. A similar pattern is observed in the downscaled but uncorrected CESM data (WRF-CESMRAW). The overestimation of quantiles between $50 \mathrm{~mm}$ and $80 \mathrm{~mm}$ is even more distinct in the WRFERA-based dataset. The quantile mapping of these data corrects the overestimation of these quantiles, as shown on the right hand side of Fig. 6. Although the fit is not perfect, there is no systematic under- or overestimation of the observed quantiles, even in the upper range of precipitation intensities.

The bias correction procedure has been applied to each event individually, and is illustrated for one particular case in Fig. 7] which shows the precipitation accumulated in a 1-day extreme event in the summer. 

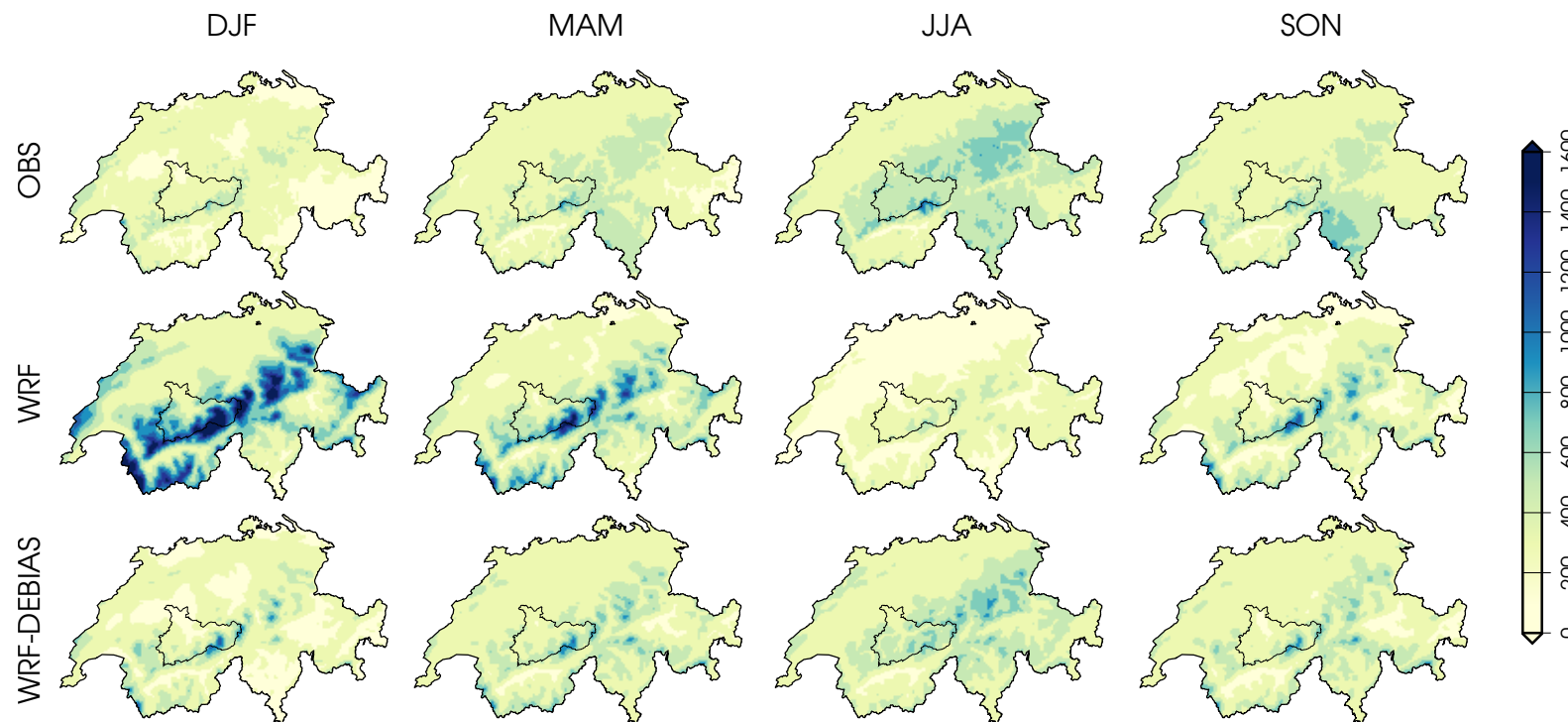

$\varepsilon$

Figure 4: Seasonally accumulated precipitation over Switzerland for the period of 1985-2005 in the OBS dataset (top), the raw WRF-CESM simulation (middle), and the former after QM correction (bottom). The Aare catchment is highlighted in the maps as the focus of this study.

\section{Annual Cycle}

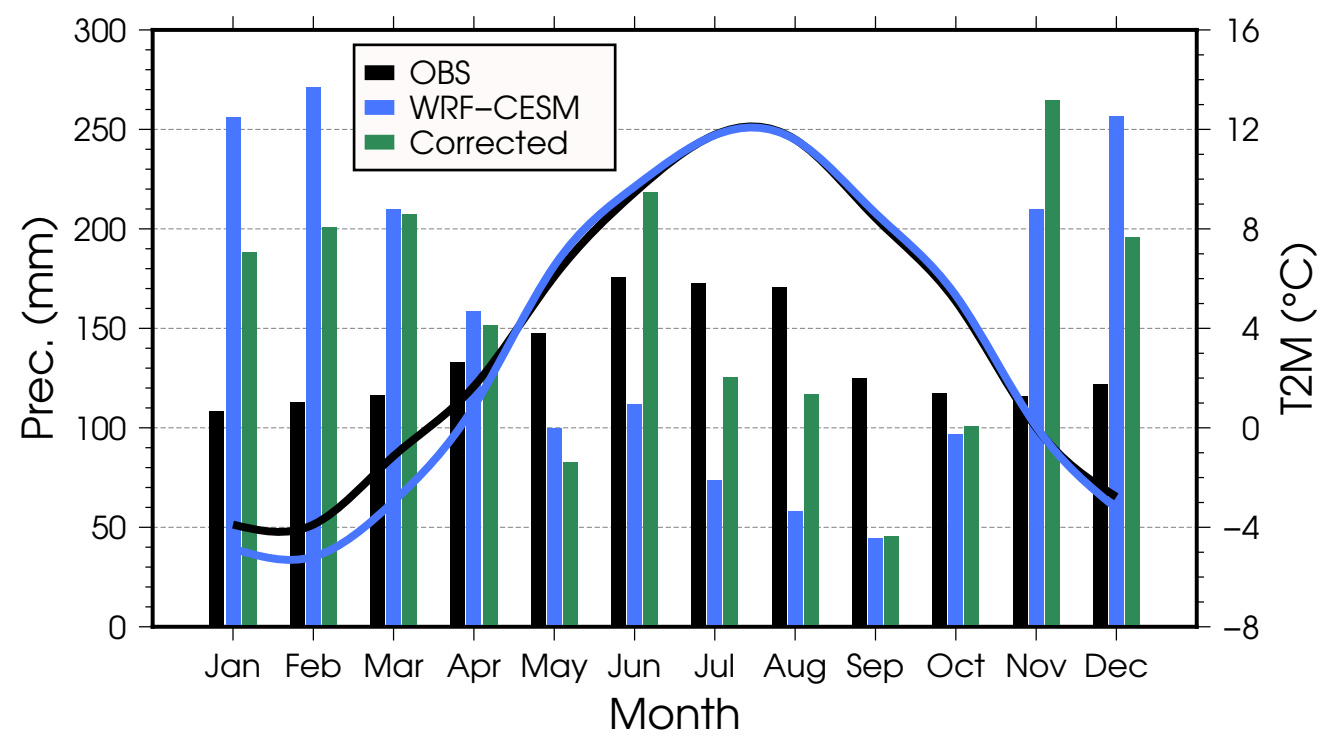

Figure 5: Annual precipitation cycle in the Aare catchment in the observational dataset, as simulated by WRF, and then after correction taking into account precipitation over the same region. The bold line represents the monthly mean temperature for the period from 1979 to 2013. 


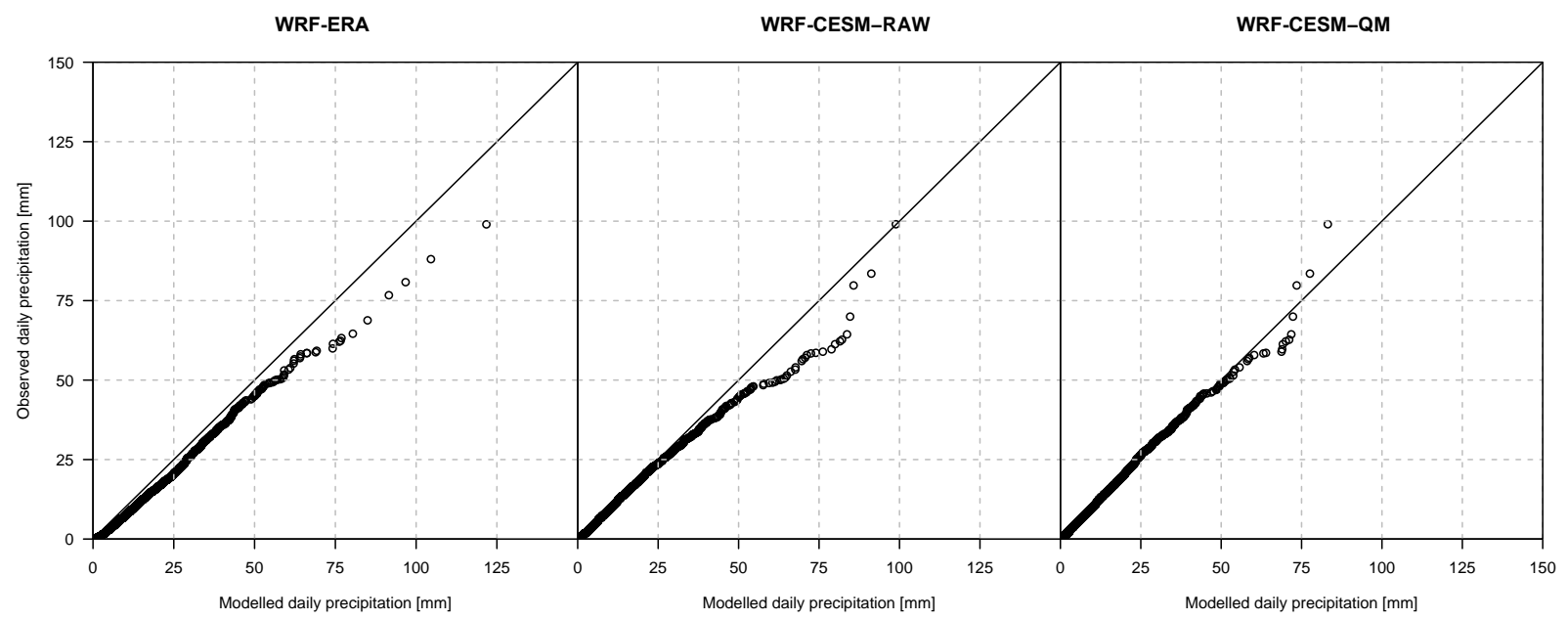

Figure 6: Quantiles of the 1-day areal mean precipitation sums of the WRF-ERA dataset, the uncorrected downscaled WRFCESM dataset and the quantile-mapped downscaled WRF-CESM-QM dataset for the study area. Each dataset covers a period of 20 years.

This event led to heavy precipitation in the central part of Switzerland, and thus it is a good case for our consideration of severe flooding in the area of interest. WRF-CESM underestimates summer precipitation; therefore this event is corrected towards higher precipitation by the bias correction method. The effect of the correction is shown in the map (Fig. 7, right panel) leading to extensive areas where precipitation exceeds $170 \mathrm{~mm}$ in 24 hours, whereas in the original model output precipitation barely reaches $120 \mathrm{~mm}$.

\subsection{Long-term characteristics of runoff simulation}

The discharge quantiles derived through the coupled hydrological-hydrodynamic modeling of the corresponding precipitation datasets are shown in Fig. 8 As the WRF-ERA based precipitation dataset is used to calibrate the hydrological model, the systematic overestimation of medium and high quantiles in the WRF-ERA precipitation is corrected to a certain degree, meaning that the overestimation of higher runoff quantiles is not as distinct as it is with precipitation. As depicted in the study design shown in Fig. 1 1 the same WRF-ERA-based calibration is applied for the hydrological modeling of the WRF-CESM-based data. In the case of raw WRF-CESM, this procedure leads to good representation of observed runoff quantiles with respect to low and medium flows, and to an underestimation of extreme flows that exceed $400 \mathrm{~m}^{3} \mathrm{~s}^{-1}$. Using the corrected version, the distribution of the runoff quantiles scatters around the observed quantiles. Although the flows between 350 and $450 \mathrm{~m}^{3} \mathrm{~s}^{-1}$ are slightly underrepresented, there is no systematic overor underestimation. Comparing the runoff quantiles of the WRF-CESM-RAW and the WRF-CESM-QM data shows the benefit of applying a quantile mapping procedure on the precipitation dataset, as this clearly improves the representation of the runoff quantiles. 


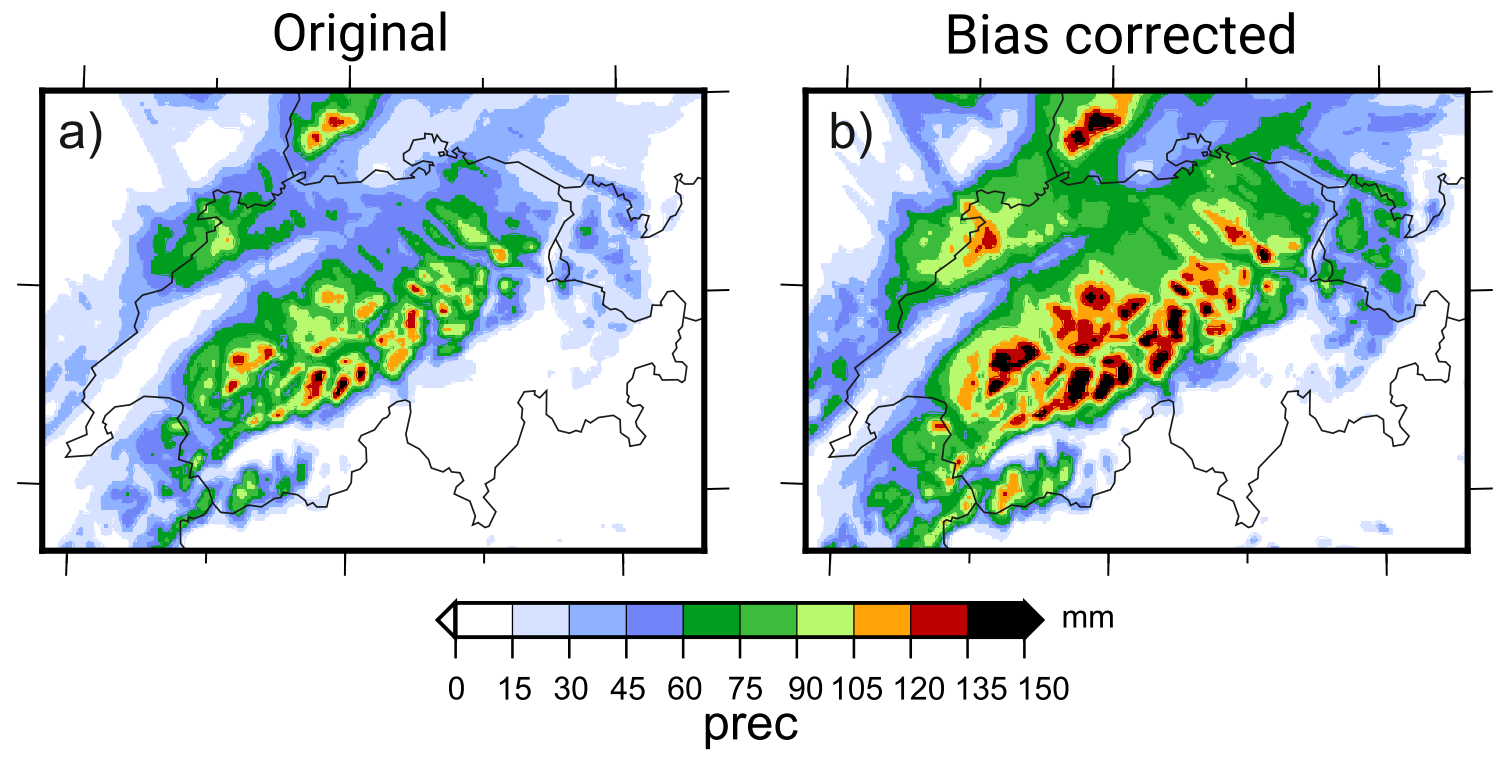

Figure 7: Example of extreme precipitation event in the summer. The panel on the left (a) shows the 1-day accumulated precipitation for an extreme event in the control simulation. The panel on the right (b) shows the precipitation field after QM correction.

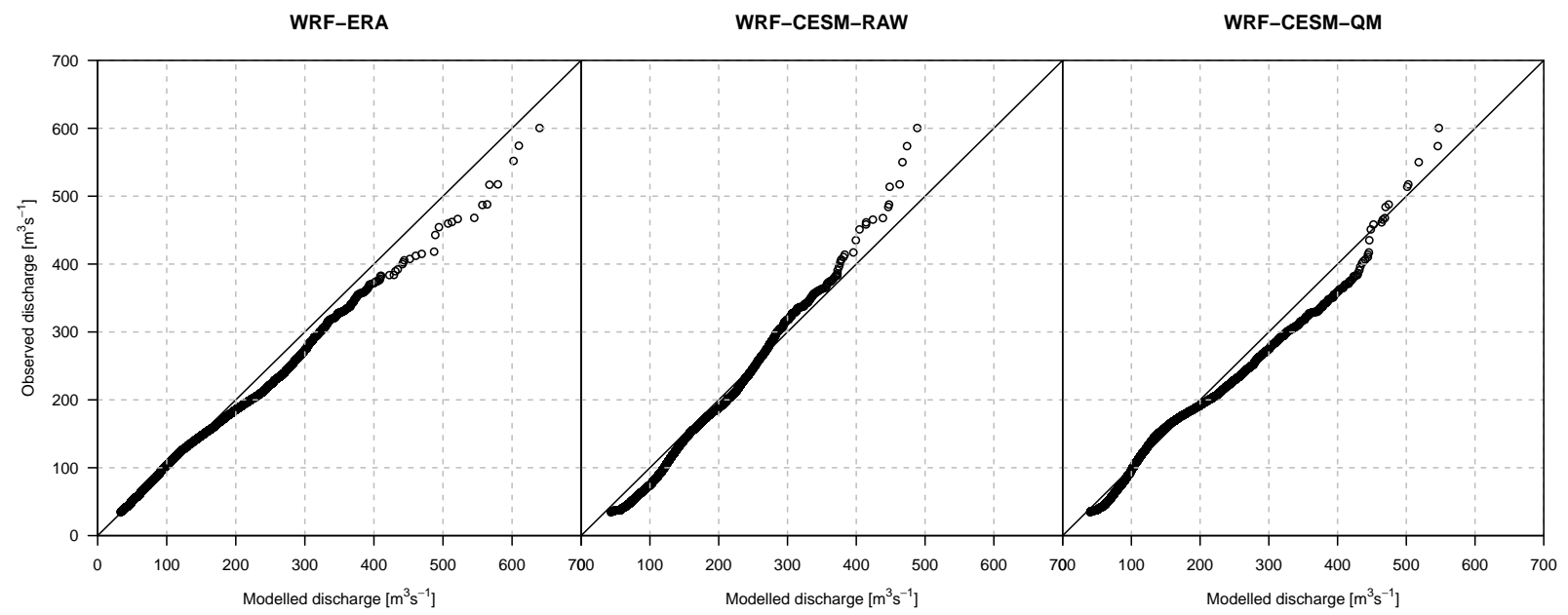

Figure 8: Long-term runoff quantiles estimated with the WRF-ERA dataset, the uncorrected downscaled CESM dataset (WRFCESM-RAW), and the quantile-mapped downscaled CESM dataset (WRF-CESM-QM) for the study area. The quantiles are compared with quantiles of the observed data. 


\subsection{Hydrometeorological extremes}

The representation of extremely high flows can be assessed by comparing the annual maximum floods es-

9. The WRF-ERA based annual maximum floods lie systematically above the observed ones, which is in line with the quantile analysis in Fig. 8. Accordingly, the corresponding tail distribution of the fitted GEV distribution is not congruent with the empirical distribution. The annual maximum floods based on the raw WRF-CESM precipitation dataset are systematically too low, and the corresponding GEV-distribution function on annual maximum floods based on the WRF-CESM dataset leads to a negative shape parameter $\xi$ and therefore to an upper-bounded distribution function, which is clearly not in line with the empirical distribution. Again, these findings correspond with the quantile comparison in Fig. 8. The annual maximum floods based on the corrected corrected WRF-CESM dataset are shown in the right part of Fig. 9. Although the modeled annual maximum floods slightly deviate from the observed ones, the corresponding fitted GEV distribution function is nearly congruent with the distribution of the observed values. This particularly applies for the tails of the distributions. This means that the hydrological and hydrodynamic modeling of the WRF-CESM-QM precipitation dataset allows for the reconstruction of both long-term runoff characteristics and extreme events, which enables the further analyses.

The seasonal distribution of the annual maximum floods is mainly determined by the catchment characteristics presented in Section 3.1. The highest extreme flows usually occur in summer. This can be explained by the high snowfall line, the glacier contribution, and the relatively high initial lake levels during summer and low initial lake levels during winter. Therefore, extreme flows during winter are rather exceptional due to these initial conditions, and the seasonal bias in the precipitation inputs shown in Fig. 5 is not directly transferred to the seasonal distribution of extreme runoffs.

The next step, following the scheme shown in Fig. 1, is the identification of extreme events in the 400-year GCM simulation. Based on the criteria detailed in Section 3.3, a number of situations potentially leading to extreme values have been selected for downscaling. Unfortunately, not all cases selected by the algorithm could be downscaled in the end due to a purely technical reason: in two cases (a 3-day event and a 10-day event, both in summer) numerical instabilities precluded the execution of the RCM. The magnitude of the precipitation as simulated by the RCM is shown for winter and summer in Fig. 10

The PDFs of precipitation are presented for the several temporal windows used in the case selection 


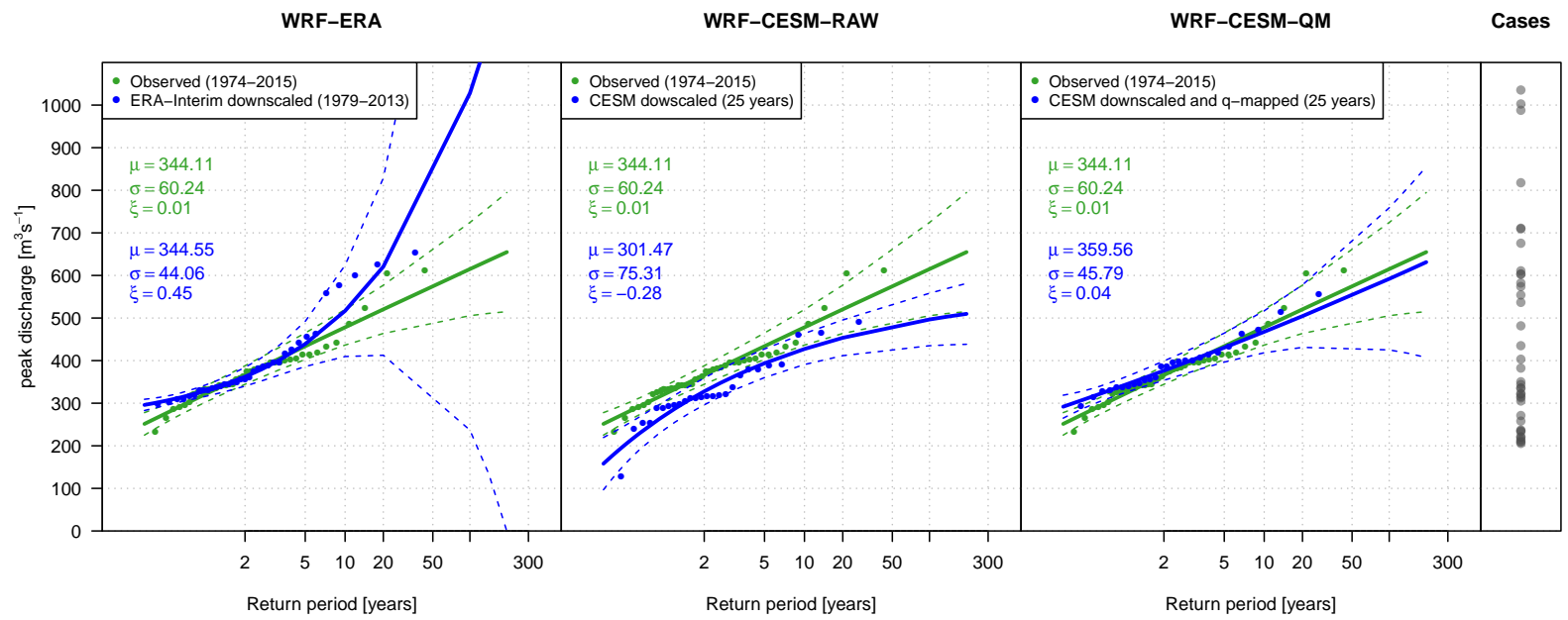

Figure 9: Comparison of annual maximum floods and corresponding fits of a generalized extreme value (GEV) distribution function. The return level plots are either based on observed data (indicated in black) or on modeled data (indicated in blue). The annual maximum floods that result from the ERA-interim dataset lie systematically above the observed ones, leading to a distinct overestimation of floods with return levels above 5 years. The annual maximum floods based on the uncorrected WRF-CESM-RAW dataset are systematically too low, leading to an underestimation of high return level floods. Applying a downscaling procedure and using the resulting WRF-CESM-QM dataset leads to good correspondence of observed and modeled annual maximum floods, and therefore to a nearly congruent fitted distribution function. The gray dots on the right side indicate the peak discharges that result from the downscaled precipitation scenarios from the 400-year GCM-run. The distribution and the magnitudes of these peak flows confirm the plausibility of the modeled events. 
algorithm (the results for spring and autumn are not shown for the sake of brevity, although they exhibit similar behavior and support similar conclusions). Firstly, a comparison of the blue and orange curves demonstrates once again, but from a different point of view, the systematic biases and seasonality issues discussed in Section 4.2. The WRF-CESM-RAW simulation underestimates precipitation for the summer and overestimates it for the winter. This is consistent across temporal windows from 1- to 10-day PDFs. Still, it should be noted that this systematic bias is corrected for each event with QM using the corresponding distributions derived for each temporal frame. This figure allows the selected events to be placed in a climatic context. Once downscaled, in all cases the precipitation values are extreme compared to the climatological mean. However, the precipitation values for these events are far lower than the expected values above the 99th percentile. The values are lower because the selected events were the four most extreme within a 400-year period, which should represent the far right tail of the 20-year climatological precipitation shown by the blue curve in each panel. As this is not always the case, it can be concluded that the events cannot be regarded as extremes with return periods of hundred of years, i.e. the event selection procedure seems to have missed such situations. This situation becomes more problematic when the spatial structure of precipitation is evaluated (not shown). In some cases the precipitation is severe when spatially averaged over a large area, as demonstrated in Fig. 10. However, due to the complexity of the topography, it occurs in areas beyond the boundaries of our area of interest, which renders the situation uninteresting for our analysis. These drawbacks do not represent a bottleneck of the model chain, as the criteria still lead to situations that are certainly extreme and of interest, but it severely limits the scope of the conclusions that can be drawn regarding the event duration these extremes represent. This issue is further discussed in the following sections.

\subsection{Damage and loss estimation}

The flood losses in the precipitation scenarios are shown in Fig. 11. Generally, the selected precipitation scenarios show high loss variability. The flood losses are in the range between 0.1 and ca. 3 billion Swiss Francs. This is related to the exposure of 800-7,600 buildings associated with 3,500-36,000 residents, with a total value of 19,000 buildings and 98,000 residents. Several factors explain the high variability in flood losses. The estimated loss depends not only on the precipitation sum, but also on the spatio-temporal pattern in rainfall, the characteristics of the values at risk in the floodplains, and the applied vulnerability functions. The precipitation event leading to the highest loss estimation has a total precipitation sum of $144 \mathrm{~mm}$ over 5 days. This is a flood event in August. Thus, the altitude of the rainfall-snowfall limit leads to a high amount of rainfall and no snowfall. In comparison, the historic flood event that caused the most flood losses in the Canton of Bern was the Flood of August 2005 with a mean areal precipitation of $160 \mathrm{~mm}$ over the study area in $48 \mathrm{~h}$. This flood event resulted in 341.3 mio. Swiss Francs in flood losses to buildings (FOEN) 2008). The discharge in Bern had a return period of approximately 150 years. Based on this comparison, 

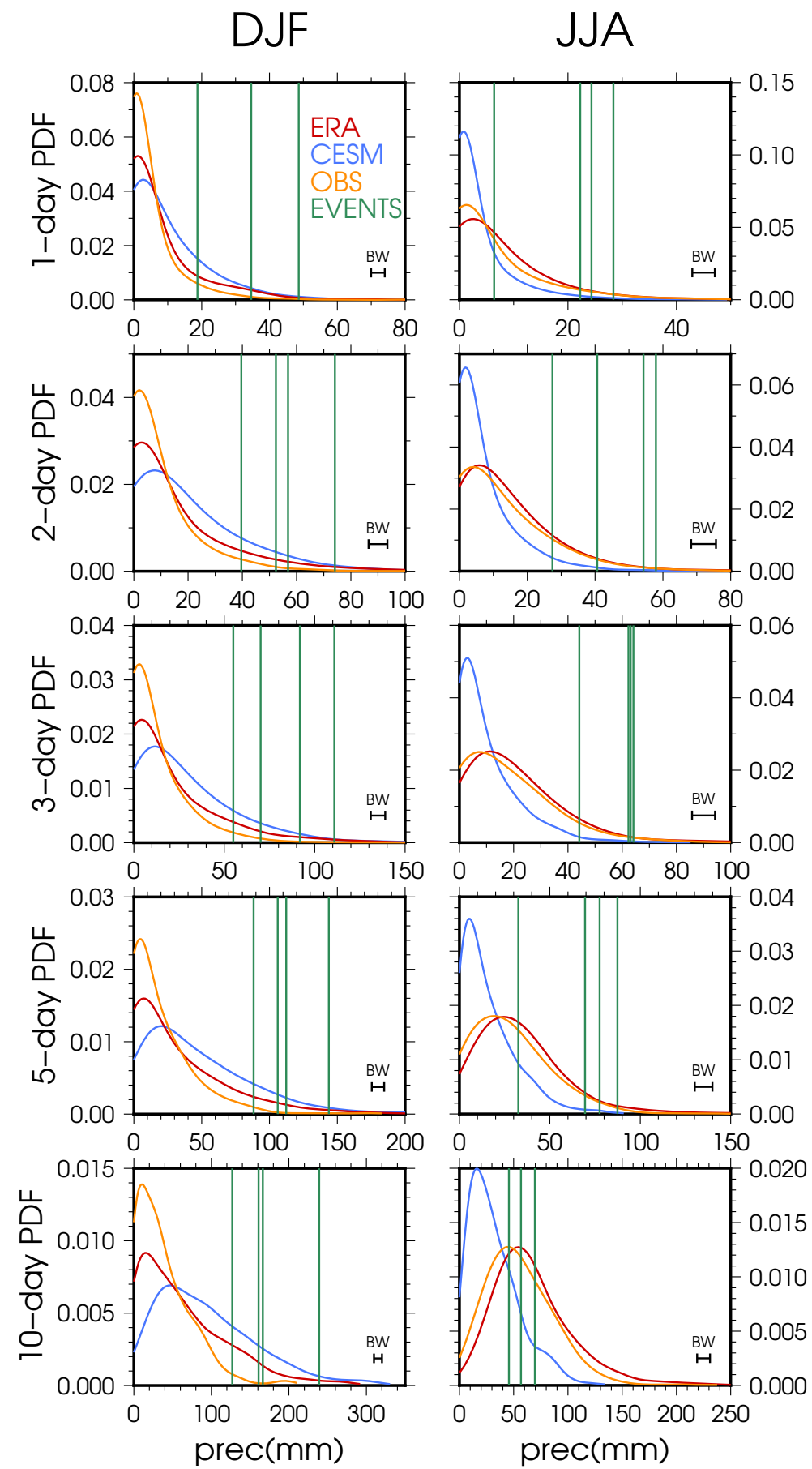

Figure 10: Probability density functions of precipitation in different temporal windows over the Aare catchment derived from WRF-ERA (red), the WRF-CESM-RAW simulation (blue), and observed data OBS (orange). To estimate the curves, Gaussian kernel density estimators are used with a bandwidth that is illustrated in the bottom-right corner of each panel. Row by row, the different panels show the winter (left) and summer (right) results for the five temporal windows considered based on the procedure described in Section 3.3 The green vertical bars represent the precipitation obtained in the selected events. Although there should be 4 bars per panel, one corresponding to each event, computational instabilities were found in some events that hampered their simulation. Intermediate seasons exhibit similar behavior and are therefore not shown. 
the scenarios simulated here are indeed extreme events. However, the total aerial precipitation is below the probable maximum precipitation in the area as indicated by WMO (2009). The second highest losses simulated here are due to a flood event in winter. This shows that extreme precipitation events in winter combined with warm air temperatures could lead to extreme flooding despite the rather dampening initial conditions in winter. However, such a scenario is beyond observed flood events in the observation period. Due to the topographic complexity of the study area, a certain variability in flood losses is related to the qvarying spatio-temporal characteristics of the derived precipitation events (Pattison et al., 2014, Emmanuel et al. 2015). This is significant because of the spatial distribution of the values at risk, i.e. the buildings. In the present study, numerous buildings are located alongside the shorelines of lake Thun and in the floodplain of Interlaken. Thus, flood loss is relatively high in case of precipitation distributions that lead to high flows in these particular areas. In addition, the estimated losses vary depending on the choice of vulnerability functions. This is in agreement with previous studies on uncertainties related to vulnerability functions (Apel et al. 2004, 2008; Merz et al., 2004, Merz \& Thieken, 2009). The present modeling approach accounts for these factors influencing extreme flood loss estimations.

\section{Discussion}

The presented model chain including simulations from atmospheric processes to local flood risk covers several orders of magnitude in space and time. Its application yielded useful information with regard to its general applicability and the modeling strategies, process representation, and issues related to the scale gap between globally running GCMs and locally occurring flood losses. These three topics are further discussed in the subsections below.

\subsection{General applicability and modeling strategy}

From a technical point of view, the results prove that coupling several models from GCM to damage models is feasible. It allows for a realistic assessment of floods and flood-prone areas, provided that each model component sufficiently represents the involved processes. Here, process representation is checked separately for each model (except the loss model) by applying an independent model calibration and validation. Once the single models are properly calibrated and validated, the performance of coupled models can be assessed using long-term characteristics of intermediate variables like precipitation and runoff.

However, a complete description of the flood risk (including frequent and extreme events) would require downscaling the full transient GCM run, which is impossible with the currently available computational resources. Therefore, a comprehensive validation of the full model chain in terms of flood risk is hardly achievable. Nevertheless, the selected scenarios provide a basis for identifying flood scenarios that exceed the protection goals of the flood defenses in the study area. In the presented case study, the flood defenses 


\section{Loss estimations for downscaled extreme events}

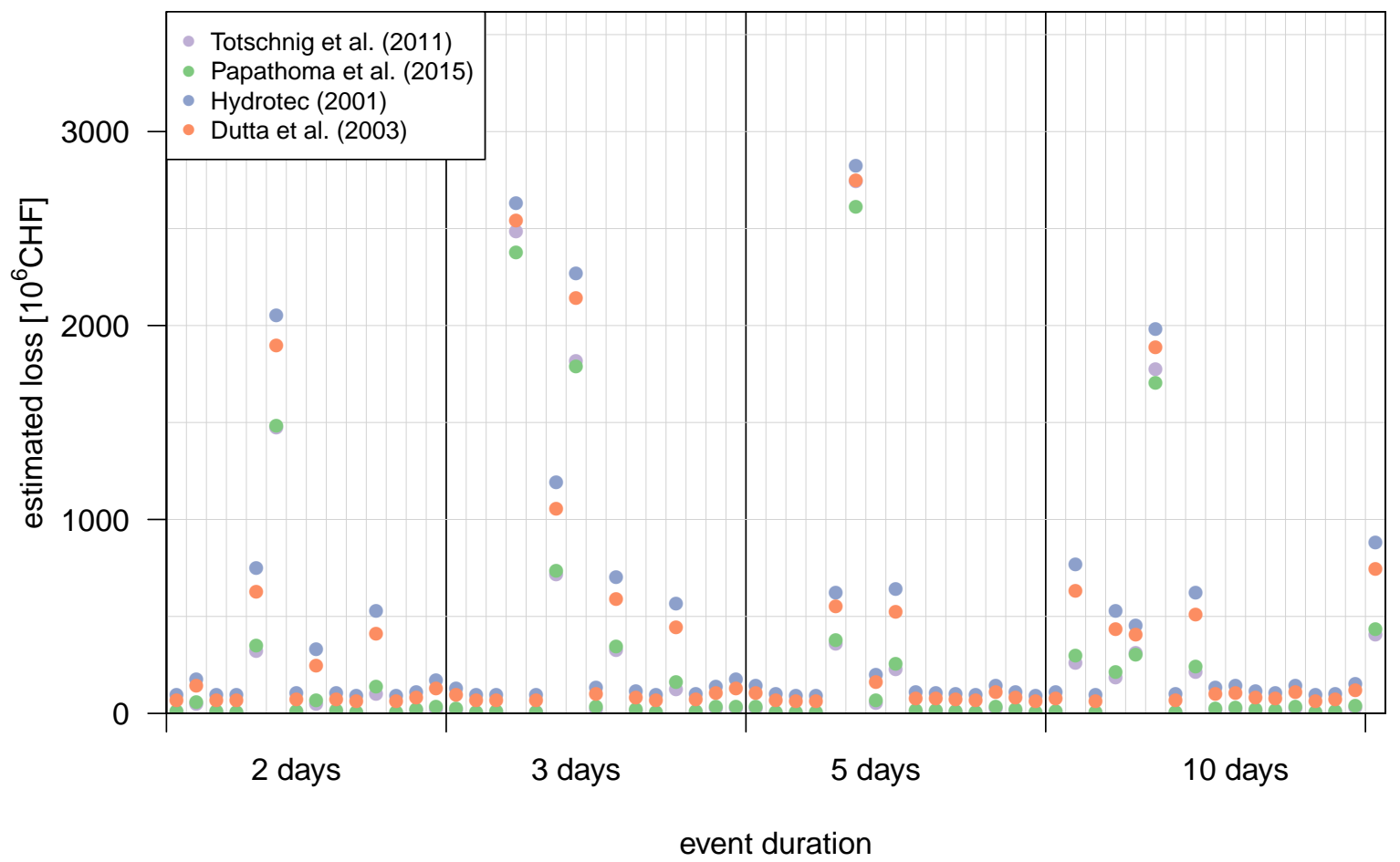

Figure 11: Loss estimations based on the hydrological and hydrodynamic modeling of the identified extreme events. The different colors indicate the applied vulnerability function. Multiple functions were applied to assess the sensitivity of the lack of validation data. 
are dimensioned by aiming to protect against flood events with return periods of roughly 80-100 years. It is shown that several precipitation scenarios lead to flow discharges higher than the carrying capacity of the river channels and thus lead to severe flooding. Thus, the presented method could complement the existing approaches for delineating residual risks, i.e. the risk that remains after the implementation of protective measures. The uncertainty in the flood loss estimation procedure can be overcome to a certain degree by applying several differing vulnerability functions, which provides some information about the model sensitivity to vulnerability functions. It can be stated that the derived flood loss estimations lie within a reasonable range when compared to the highest observed events.

The GCM simulation that serves as a basis for identifying extreme precipitation events spans 400 years of control run. Current computational resources do not allow such a long time period to be downscaled. Therefore, a few sub-samples of interest must be selected from the total GCM time series. A crucial point in this strategy is that the time frames for downscaling have to be chosen before downscaling is applied, therefore without certainty that the pre-selected event will correspond to an extreme situation once downscaled. It is assumed that the amount of precipitation modeled by the GCM and averaged over the study area is a good indicator for downscaled extreme precipitation. This is qualitatively true, as can be observed in Fig. 10, where the selected events are found in the right tail of the rainfall distribution. However, the events correspond to lower percentiles than expected (in all cases below the 99th). This is in part because in some cases the downscaled extreme precipitation takes place outside the area of interest, i.e. outside the Aare catchment, but also because in few events there is no extreme precipitation event at all. The efficiency of case selection using the much shorter but available continuous simulation in the period 1986-2005 can be estimated to some extent. The correlation between the GCM averaged series and the downscaled precipitation for the Aare catchment is 0.21 . Further, the days within this period whose precipitation is above the 90th percentile in both datasets are identified. It turns out that only $20 \%$ of days belong simultaneously to the GCM and the downscaled series, i.e. about $80 \%$ of days whose actual precipitation was above the 90 th percentile in the downscaled control period were not flagged by the selection algorithm described in Section 3.3 . This simple analysis clearly illustrates the important differences between the GCM and RCM outputs, and points out severe limitations in the method used to identify candidates to severe precipitation episodes. At the same time it demonstrates the necessity of downscaling strategies. Therefore, the identification of events in the long-term GCM simulation for downscaling is a crucial step in overcoming the scale gap between globally running GCMs and local flood impacts that deserves important improvements. If the aim of future modelling exercises is to characterise situations that are realistically representative of extreme events with long return periods, then this difficulty can become an important bottleneck of the case study approach. Therefore, further research is needed to refine the selection of candidates for extreme events at regional scales.

The aim of this study, which has conditioned the chosen modeling strategy, is to keep the physical 
consistency over all modeling steps from atmospheric to flood loss modeling. Unfortunately all climate models are affected by structural limitations that lead to biases of different intensities that can condition its use in certain applications. Bias-correction techniques minimise such problems, but at the expense of affecting the physical consistency (Maraun, 2016). Therefore a compromise has to be established. The biases present in the WRF-CESM simulation pertain especially the representation of the annual cycle, and are noticeable enough to call for the use of bias-correction techniques. However, the QM method has not been applied in a per-grid basis. This minimizes the risk of over-fitting of the raw precipitation product to the observations, which would otherwise destroy the spatial coherence provided by the dynamical downscaling, being an important issue further discussed by Gómez-Navarro et al. (2018). The spatio-temporal structure as well as the magnitude of the modeled precipitation is physically determined. No further assumptions have to be made, and no further processing steps beyond the calibration of the models to fit observations have to be applied. This is a clear benefit compared to other precipitation modeling approaches, e.g. stochastic weather generators (e.g. Leander et al., 2005; Semenov, 2008) or similar stochastic approaches (e.g. Foufoula-Georgiou, 1989, Vandenberghe et al. 2010).

The hydrological and hydrodynamic models can be calibrated and validated using observed discharge data, which is a widely accepted and well-researched approach. However, assessing the long-term runoff characteristics of a meso-scale catchment requires modeling a time series of several years, which calls for the application of a 1D hydrodynamic model. To model long time series with a more detailed 2D hydrodynamic model would exponentially increase computation time and is therefore not feasible. A 2D representation, however, incorporates lateral flows and therefore remarkably increases the accuracy of estimating flooding extent on building scale and improves the loss estimation. One way to overcome the tradeoff between computation time and degree of detail is to combine a $1 \mathrm{D}$ model with a $2 \mathrm{D}$ model. The $1 \mathrm{D}$ model is used to model the long-term runoff characteristics. The $2 \mathrm{D}$ model is only used for inundation modeling in case of extreme events, where the 1D model outputs serve as boundary conditions. Eventually, the output of the 2D model builds the basis for loss estimation. Such a modeling approach combines reasonable computation times for modeling long-term runoff characteristics and detailed model outputs as a basis for loss modeling.

The limitation of loss modeling lies in the unknown uncertainty of the vulnerability functions. This issue can be resolved by increasing the quantity and quality of observational data, which provide the basis for empirically deducing vulnerability functions. Alternatively, Schröter et al. (2014) showed that the predictive capability of the loss model can be improved by incorporating more explanatory variables or by choosing a Bayesian network-based loss modeling approach. However, these approaches do not help overcome the issues associated with a lack of validation data. 


\subsection{Representation of atmospheric and hydrological processes}

The atmospheric processes in the GCM are explicitly resolved based on basic, well-established physical laws and are therefore coherently structured in space and time according to physical boundaries and climate forcings. However, the coarse resolution of global models hampers their direct application in areas with complex topography. Likewise, the dynamical downscaling step solves similar sets of equations as the GCM, therefore maintaining this coherent structure. RCMs have the advantage of improving the representation of simulated physical processes in case of strong topographic influences since the underlying model topography is more finely resolved and directly incorporated. Thus, fields produced by a GCM and downscaled by a RCM are coherent in their spatio-temporal behavior. However, model deficiencies and errors attributable to to be addressed.

In this particular application, the comparison of precipitation intensity quantiles showed that the downscaled WRF-CESM-RAW precipitation time series does not sufficiently represent the observed long-term rainfall characteristics over the study area in a 20-year climatic simulation. Therefore, a variant of quantile mapping correction is applied in order to minimize perturbations in the physical consistency while compensating for systematic biases. The WRF-CESM-QM dataset is more appropriate for a description of the rainfall characteristics for all intensities, even in a topographically complex study area, and therefore leads to plausible precipitation event estimations in mountainous regions, which justifies the application of such a complex model chain. This is certainly in line with other applications of downscaled rainfall data (Bowden et al., 2016, García-Valdecasas Ojeda et al., 2017, Gudmundsson et al., 2012, Maule et al., 2013. Jakob Themeßl et al., 2011, among others). Applications based on CESM datasets are spatially and temporally coherent on a large scale. Furthermore, the empirical frequencies of particular synoptic situations and seasonal patterns are inherently incorporated and do not have to be taken into additional consideration.

The simulation of hydrological processes by conceptual hydrological modeling is well established for normal flows as well as for extreme events. For the present study, the appropriateness of conceptual hydrological modeling is demonstrated by the good skill scores that resulted from the model calibration and validation for each sub-catchment. However, the hydrological model PREVAH (Viviroli et al., 2009b) applied in this study is a conceptual, semi-deterministic model. This means that many processes, e.g. evapotranspiration or soil water flows, are incorporated using empirical formulas rather than deterministic calculations. Furthermore, the primary model output is a discharge time series for the outlet of a pre-defined catchment, with no direct deterministic flow representation inside the catchment. In consequence, the presented approach does not allow for loss estimations for areas lying within the hydrologically modeled sub-catchments described in Section 3.1 and shown in Fig. 3. The hydrodynamic model provides a better physical representation of the flows within and around the riverbed. In this way, runoff conditions are calculated precisely in terms 
be crucial for runoff determination (Felder et al. 2017$)$ are also incorporated. This model set-up calls for careful planning of the spatial arrangement of the hydrological and hydrodynamic models. The hydrological model shall be applied in areas where runoff formation takes place and where ideally the damage potential is low. The hydrodynamic model must be applied in all potentially flood-prone areas and in areas with a high damage potential.

The actual setup of the 2D inundation model nested into the hydrologic-hydrodynamic model chain reliably represents the flooding processes in the floodplains and allows for flow depths to be attributed to the individual buildings. Thus, this setup allows for flood losses to be estimated at building scale with an aggregation of the object-related losses to the basin scale. However, the deterministic approach of the model chain ends with the attribution of flow depths to buildings. The subsequent loss estimation is partly based on empirical stage-damage functions, and thus the last step in the model chain differs from the previous physically based approaches.

\subsection{Temporal and spatial scales}

As indicated in Table 1, the resolutions of the applied models range from $100 \mathrm{~km}$ to $10 \mathrm{~m}$ in space and from days to seconds in time. The present study presents two key considerations for overcoming these scale gaps. Firstly, incorporating intermediate models enables capturing flood-triggering processes that occur on intermediate scales. In the present case, the hydrological model simulates the catchment reaction to the precipitation events on an hourly resolution in time and on a $2 \mathrm{~km}$ resolution in space. The hydrodynamic model covers the next scale gap, as it simulates the runoff processes at a resolution of $10 \mathrm{~s}$ and $10 \mathrm{~m}$. Secondly, the application of a dynamic downscaling technique followed by QM is important and, when necessary, the long-term characteristics of precipitation fields should be debiased.

The presented model chain has a relatively high level of flexibility when it comes to temporal scale. As soon as all sub-modules are to be run on sub daily temporal scales, the time steps of all subsequent models can be adapted to the necessary time step. In practice, the small catchments (below $200 \mathrm{~km}^{2}$ ) require an hourly time step for reliable estimation of peak river discharges.

\section{Conclusions}

This paper presents a model chain able to bridge the spatial scales from global circulation down to the building scale and from hundreds of years to single flood events. To our knowledge, this is the first study dealing with such a wide range of scales. The presented approach is suited for the identification of extreme flood events. A model chain from the atmosphere to flood risk is a potentially useful additional method for characterizing design floods with very low return periods in planning disaster risk reduction. With this temporal flexibility and the coherence of the spatio-temporal rainfall patterns, the approach is promising for 
future flood risk assessments. A coupled model chain, linking atmospheric processes and synoptic situations to local flood losses, is particularly promising for risk identification for insurance portfolios. In contrast to approaches using weather generators, the presented approach is physically more consistent in mountainous regions where topographical effects are relevant for locally high precipitation intensities. Although the approach is promising, further improvements are required before it is suitable for practical application. First, the use of bias-correction techniques is necessary to remove prominent biases in downscaled precipitation, which precludes the pure physical consistency of the model chain. Second, the process of selecting extreme events to be dynamically downscaled is critical for the extrapolability of the results from few cases to conclusions regarding the full period spanned by the GCM. The simple selection procedure applied in this study leads to downscaled events that are not as extreme as expected, indicating that the event selection strategy should be improved in future studies.

\section{Acknowledgments}

We thank the Federal Office of Topography for providing the corresponding spatial data, the Federal Office for Statistics for providing residential statistics, as well as the Federal Office of Meteorology and Climatology for providing rainfall data and access to the ERA-Interim dataset, and the Mobiliar Lab for Natural Risks for supporting the study. JJGN acknowledges the CARM for the funding provided through the Seneca Foundation (project 20022/SF/16).

\section{References}

Ali, A., Di Baldassarre, G., \& Solomatine, D. P. (2015). Testing different cross-section spacing in 1d hydraulic modelling: a case study on johor river, malaysia. Hydrological Sciences Journal, 60, 351-360. doi 10.1080/02626667.2014.889297.

Altarejos-García, L., Martínez-Chenoll, M. L., Escuder-Bueno, I., \& Serrano-Lombillo, A. (2012). Assessing the impact of uncertainty on flood risk estimates with reliability analysis using 1-d and 2-d hydraulic models. Hydrology and Earth System Sciences, 16, 1895-1914. doi 10.5194/hess-16-1895-2012.

Apel, H., Aronica, G. T., Kreibich, H., \& Thieken, A. H. (2009). Flood risk analyses-how detailed do we need to be? Natural Hazards, 49, 79-98. doi 10.1007/s11069-008-9277-8.

Apel, H., Merz, B., \& Thieken, A. H. (2008). Quantification of uncertainties in flood risk assessments. International Journal of River Basin Management, 6, 149-162. doi 10.1080/15715124.2008.9635344

Apel, H., Thieken, A. H., Merz, B., \& Blöschl, G. (2004). Flood risk assessment and associated uncertainty. Natural Hazards and Earth System Science, 4, 295-308. doi 10.5194/nhess-4-295-2004

Ban, N., Schmidli, J., \& Schr, C. (2014). Evaluation of the convection-resolving regional climate modeling approach in decadelong simulations. Journal of Geophysical Research: Atmospheres, 119, 78897907. doi 10.1002/2014JD021478

Bates, P., \& de Roo, A. (2000). A simple raster-based model for flood inundation simulation. Journal of Hydrology, 236, 54-77. doi 10.1016/S0022-1694(00)00278-X.

Bouwer, L. M. (2013). Projections of future extreme weather losses under changes in climate and exposure. Risk Analysis, 33, 915-930. doi $10.1111 / \mathrm{j} .1539-6924.2012 .01880 . \mathrm{x}$ 
Bowden, J. H., Talgo, K. D., Spero, T. L., \& Nolte, C. G. (2016). Assessing the Added Value of Dynamical Downscaling Using the Standardized Precipitation Index. Advances in Meteorology, 2016, 1-14. doi 10.1155/2016/8432064

Bracegirdle, T. J., Shuckburgh, E., Sallee, J.-B., Wang, Z., Meijers, A. J. S., Bruneau, N., Phillips, T., \& Wilcox, L. J. (2013). Assessment of surface winds over the atlantic, indian, and pacific ocean sectors of the southern ocean in CMIP5 models: historical bias, forcing response, and state dependence. Journal of Geophysical Research-Atmospheres, 118, 547562. doi $10.1002 /$ jgrd.50153

Brandimarte, L., \& Di Baldassarre, G. (2012). Uncertainty in design flood profiles derived by hydraulic modelling. Hydrology Research, 43, 753. doi $10.2166 / \mathrm{nh} .2011 .086$

Camici, S., Brocca, L., Melone, F., \& Moramarco, T. (2014). Impact of climate change on flood frequency using different climate

models and downscaling approaches. Journal of Hydrologic Engineering, 19, 04014002. doi 10.1061/(ASCE) HE.1943-5584. 0000959

Cammerer, H., Thieken, A. H., \& Lammel, J. (2013). Adaptability and transferability of flood loss functions in residential areas. Natural Hazards and Earth System Science, 13, 3063-3081. doi 10.5194/nhess-13-3063-2013.

Castellarin, A., Di Baldassare, G., Bates, P. D., \& Brath, A. (2009). Optimal cross-sectional spacing in preissmann scheme 1d hydrodynamic models. Journal of Hydraulic Engineering, 135, 96-105. doi 10.1061/(ASCE) 0733-9429(2009) 135:2 (96)

Chen, J., Brissette, F. P., Chaumont, D., \& Braun, M. (2013). Performance and uncertainty evaluation of empirical downscaling methods in quantifying the climate change impacts on hydrology over two north american river basins. Journal of Hydrology, (pp. 200-214). doi 10.1016/j.jhydrol.2012.11.062

Coles, S. (2004). An introduction to statistical modelling of extreme values. London, UK: Springer Press.

Cook, A., \& Merwade, V. (2009). Effect of topographic data, geometric configuration and modeling approach on flood inundation mapping. Journal of Hydrology, 377, 131-142. doi 10.1016/j.jhydrol.2009.08.015

Das, T., Maurer, E. P., Pierce, D. W., Dettinger, M. D., \& Cayan, D. R. (2013). Increases in flood magnitudes in california under warming climates. Journal of Hydrology, 501, 101-110. doi 10.1016/j . jhydrol.2013.07.042

Dee, D. P., Uppala, S. M., Simmons, A. J., Berrisford, P., Poli, P., Kobayashi, S., Andrae, U., Balmaseda, M. A., Balsamo, G., Bauer, P., Bechtold, P., Beljaars, A. C. M., van de Berg, L., Bidlot, J., Bormann, N., Delsol, C., Dragani, R., Fuentes, M., Geer, A. J., Haimberger, L., Healy, S. B., Hersbach, H., Hólm, E. V., Isaksen, L., Kå llberg, P., Köhler, M., Matricardi, M., McNally, A. P., Monge-Sanz, B. M., Morcrette, J.-J., Park, B.-K., Peubey, C., de Rosnay, P., Tavolato, C., Thépaut, J.-N., \& Vitart, F. (2011). The ERA-Interim reanalysis: Configuration and performance of the data assimilation system. Quart. J. Roy. Meteor. Soc., 137, 553-597. doi 10.1002/qj.828

Di Baldassarre, G., Schumann, G., Bates, P. D., Freer, J. E., \& Beven, K. J. (2010). Flood-plain mapping: a critical discussion of deterministic and probabilistic approaches. Hydrological Sciences Journal, 55, 364-376. doi 10.1080/02626661003683389

Duan, J. G., Bai, Y., Dominguez, F., Rivera, E., \& Meixner, T. (2017). Framework for incorporating climate change on 730 flood magnitude and frequency analysis in the upper santa cruz river. Journal of Hydrology, 549, 194-207. doi 10.1016/j. jhydrol.2017.03.042

Dutta, D., Herath, S., \& Musiake, K. (2003). A mathematical model for flood loss estimation. Journal of Hydrology, 277, 24-49. doi 10.1016/S0022-1694(03)00084-2.

Dutta, D., Teng, J., Vaze, J., Lerat, J., Hughes, J., \& Marvanek, S. (2013). Storage-based approaches to build floodplain inundation modelling capability in river system models for water resources planning and accounting. Journal of Hydrology, 504, 12-28. doi $10.1016 / \mathrm{j} \cdot \mathrm{jhydrol} .2013 .09 .033$

DWA (2012). Ermittlung von hochwasserwahrscheinlichkeiten.

Emmanuel, I., Andrieu, H., Leblois, E., Janey, N., \& Payrastre, O. (2015). Influence of rainfall spatial variability on rainfall口 runoff modelling: Benefit of a simulation approach? Journal of Hydrology, 531, 337-348. doi 10.1016/j.jhydrol.2015.04. 058 
Ernst, J., Dewals, B. J., Detrembleur, S., Archambeau, P., Erpicum, S., \& Pirotton, M. (2010). Micro-scale flood risk analysis based on detailed 2d hydraulic modelling and high resolution geographic data. Natural Hazards, 55, $181-209$. doi $10.1007 / \mathrm{s} 11069-010-9520-\mathrm{y}$

Falter, D., Schröter, K., Dung, N. V., Vorogushyn, S., Kreibich, H., Hundecha, Y., Apel, H., \& Merz, B. (2015). Spatially coherent flood risk assessment based on long-term continuous simulation with a coupled model chain. Journal of Hydrology, 524, 182-193. doi $10.1016 / \mathrm{j} \cdot$ jhydrol.2015.02.021

Felder, G., \& Weingartner, R. (2017). Assessment of deterministic pmf modelling approaches. Hydrological Sciences Journal, 62, 1591-1602. doi $10.1080 / 02626667.2017 .1319065$

Felder, G., Zischg, A., \& Weingartner, R. (2017). The effect of coupling hydrologic and hydrodynamic models on pmf estimation. Journal of Hydrology, 550, 157-165. doi 10.1016/j.jhydrol.2017.04.052

Fiseha, B. M., Setegn, S. G., Melesse, A. M., Volpi, E., \& Fiori, A. (2014). Impact of climate change on the hydrology of upper tiber river basin using bias corrected regional climate model. Water Resources Management, 28, 1327-1343. doi $10.1007 / \mathrm{s} 11269-014-0546-\mathrm{x}$

FOEN (2008). Event-analysis of the 2005 flood: Part 2: Analysis of processes, measures and hazards.

FOEN (2009). Event-analysis of the august 2007 flood.

Foufoula-Georgiou, E. (1989). A probabilistic storm transposition approach for estimating exceedance probabilities of extreme precipitation depths. Water Resources Research, 25, 799-815.

Fowler, H. J., Blenkinsop, S., \& Tebaldi, C. (2007). Linking climate change modelling to impacts studies: recent advances in

n downscaling techniques for hydrological modelling. International Journal of Climatology, 27, 1547-1578. doi 10.1002/joc. 1556

Furrer, E. M., \& Katz, R. W. (2008). Improving the simulation of extreme precipitation events by stochastic weather generators. Water Resources Research, 44. doi 10.1029/2008WR007316

García-Valdecasas Ojeda, M., Gámiz-Fortis, S. R., Castro-Díez, Y., \& Esteban-Parra, M. J. (2017). Evaluation of wrf capability to detect dry and wet periods in spain using drought indices. Journal of Geophysical Research: Atmospheres, 122, 1569-1594. doi $10.1002 / 2016$ JD025683

Gómez-Navarro, J. J., Raible, C. C., Bozhinova, D., Martius, O., Garca Valero, J. A., \& Montvez, J. (2018). A new region-aware bias correction method for simulated precipitation in the alpine region. Geoscientific Model Development, .

Gómez-Navarro, J. J., Raible, C. C., \& Dierer, S. (2015). Sensitivity of the WRF model to PBL parametrisations and

口 nesting techniques: evaluation of wind storms over complex terrain. Geosci. Model Dev., 8, 3349-3363. doi 10.5194/ gmd-8-3349-2015

Gudmundsson, L., Bremnes, J. B., Haugen, J. E., \& Engen-Skaugen, T. (2012). Technical Note: Downscaling RCM precipitation to the station scale using statistical transformations a comparison of methods. Hydrol. Earth Syst. Sci., 16, 3383-3390. doi $10.5194 /$ hess-16-3383-2012

Hirabayashi, Y., Mahendran, R., Koirala, S., Konoshima, L., Yamazaki, D., Watanabe, S., Kim, H., \& Kanae, S. (2013). Global flood risk under climate change. Nature Climate Change, 3, 816-821. doi 10.1038/nclimate1911

Hurrell, J. W., Holland, M. M., Gent, P. R., Ghan, S., Kay, J. E., Kushner, P. J., Lamarque, J.-F., Large, W. G., Lawrence, D., Lindsay, K., Lipscomb, W. H., Long, M. C., Mahowald, N., Marsh, D. R., Neale, R. B., Rasch, P., Vavrus, S., Vertenstein, M., Bader, D., Collins, W. D., Hack, J. J., Kiehl, J., \& Marshall, S. (2013). The community earth system model: A framework for collaborative research. Bulletin of the American Meteorological Society, 94, 1339-1360.

Hydrotec (2001). Hochwasser-aktionsplan angerbach. teil 1: Berichte und anlagen.

IPCC (2014). Climate change 2014: The physical science basis: Summary for policymakers. Geneva, Switzerland.

Jakob Themeßl, M., Gobiet, A., \& Leuprecht, A. (2011). Empirical-statistical downscaling and error correction of daily precipitation from regional climate models. International Journal of Climatology, 31, 1530-1544. doi 10.1002/joc.2168 
Kara, F., Yucel, I., \& Akyurek, Z. (2016). Climate change impacts on extreme precipitation of water supply area in istanbul: use of ensemble climate modelling and geo-statistical downscaling. Hydrological Sciences Journal, 61, 2481-2495. doi 10 . $1080 / 02626667.2015 .1133911$

Keller, M., Fuhrer, O., Schmidli, J., Stengel, M., Stockli, R., \& Schaer, C. (2016). Evaluation of convection-resolving models using satellite data: The diurnal cycle of summer convection over the alps. Meteorologische Zeitschrift, 25, 165-179.

Kim, J., Warnock, A., Ivanov, V. Y., \& Katopodes, N. D. (2012). Coupled modeling of hydrologic and hydrodynamic processes including overland and channel flow. Advances in Water Resources, 37, 104-126. doi 10.1016/j.advwatres.2011.11.009

Kundzewicz, Z. W., Kanae, S., Seneviratne, S. I., Handmer, J., Nicholls, N., Peduzzi, P., Mechler, R., Bouwer, L. M., Arnell, N., Mach, K., Muir-Wood, R., Brakenridge, G. R., Kron, W., Benito, G., Honda, Y., Takahashi, K., \& Sherstyukov, B. (2013). Flood risk and climate change: global and regional perspectives. Hydrological Sciences Journal, 59, 1-28. doi $10.1080 / 02626667.2013 .857411$

Kundzewicz, Z. W., \& Stakhiv, E. Z. (2010). Are climate models "ready for prime time" in water resources management applications, or is more research needed? Hydrological Sciences Journal, 55, 1085-1089. doi 10.1080/02626667.2010.513211

Laganier, O., Ayral, P. A., Salze, D., \& Sauvagnargues, S. (2014). A coupling of hydrologic and hydraulic models appropriate

1. for the fast floods of the gardon river basin (france). Natural Hazards and Earth System Science, 14, 2899-2920. doi 10. 5194/nhess-14-2899-2014

800 Langousis, A., Mamalakis, A., Deidda, R., \& Marrocu, M. (2016). Assessing the relative effectiveness of statistical downscaling and distribution mapping in reproducing rainfall statistics based on climate model results. Water Resources Research, 52, 471-494. doi $10.1002 / 2015$ WR017556

Leander, R., Buishand, A., Aalders, P., \& Wit, M. D. (2005). Estimation of extreme floods of the river meuse using a stochastic weather generator and a rainfall-runoff model / estimation des crues extrêmes de la meuse à l'aide d'un générateur stochastique de variables météorologiques et d'un modèle pluie-débit. Hydrological Sciences Journal, 50. doi 10.1623/hysj . 2005.50.6.1089

Lehner, F., Joos, F., Raible, C. C., Mignot, J., Born, A., Keller, K. M., \& Stocker, T. F. (2015). Climate and carbon cycle dynamics in a CESM simulation from 850 to 2100 CE. Earth System Dynamics, 6, 411-434.

Lerat, J., Perrin, C., Andréassian, V., Loumagne, C., \& Ribstein, P. (2012). Towards robust methods to couple lumped rainfall-runoff models and hydraulic models: A sensitivity analysis on the illinois river. Journal of Hydrology, 418-419, 123-135. doi $10.1016 / j \cdot j h y d r o l .2009 .09 .019$

Li, F., Xu, Z., Liu, W., \& Zhang, Y. (2014). The impact of climate change on runoff in the yarlung tsangpo river basin in the tibetan plateau. Stochastic Environmental Research and Risk Assessment, 28, 517-526. doi 10.1007/s00477-013-0769-z

Madsen, H., Lawrence, D., Lang, M., Martinkova, M., \& Kjeldsen, T. R. (2014). Review of trend analysis and climate change

projections of extreme precipitation and floods in europe. Journal of Hydrology, 519, 3634-3650. doi 10.1016/j.jhydrol. 2014.11 .003

Makkonen, L. (2008). Bringing closure to the plotting position controversy. Communications in Statistics - Theory and Methods, 37, 460-467. doi 10.1080/03610920701653094

Maraun, D. (2016). Bias correcting climate change simulations a critical review. Current Climate Change Reports, $2,211220$. doi doi.org/10.1007/s40641-016-0050-x

Maule, C. F., Thejll, P., Christensen, J. H., Svendsen, S. H., \& Hannaford, J. (2013). Improved confidence in regional climate model simulations of precipitation evaluated using drought statistics from the ENSEMBLES models. Climate Dynamics, 40, 155-173. doi $10.1007 / \mathrm{s} 00382-012-1355-7$

Mejia, A. I., \& Reed, S. M. (2011). Evaluating the effects of parameterized cross section shapes and simplified routing with

825 a coupled distributed hydrologic and hydraulic model. Journal of Hydrology, 409, 512-524. doi 10.1016/j.jhydrol.2011. 08.050 
Merz, B., Kreibich, H., Thieken, A., \& Schmidtke, R. (2004). Estimation uncertainty of direct monetary flood damage to buildings. Natural Hazards and Earth System Science, 4, 153-163. doi 10.5194/nhess-4-153-2004

Merz, B., \& Thieken, A. H. (2009). Flood risk curves and uncertainty bounds. Natural Hazards, 51, 437-458. doi 10.1007/ 830 S11069-009-9452-6

Messmer, M., Gomez-Navarro, J. J., \& Raible, C. C. (2017). The impact of Vb-cyclones to ocean temperature and soil moisture changes in sensitivity experiments with WRF. Earth System Dynamics, 8, 477-493. doi 10.5194/esd-8-477-2017

MeteoSwiss (2015). Documentation of meteoswiss grid-data products: Daily precipitation (final analysis): Rhiresd. URL: http://www.ifu.ethz.ch/hydrologie/research/research_data/proddocrhiresd.pdf.

Neal, J., Schumann, G., \& Bates, P. (2012). A subgrid channel model for simulating river hydraulics and floodplain inundation over large and data sparse areas. Water Resources Research, 48, 619. doi 10.1029/2012WR012514

Orth, R., Staudinger, M., Seneviratne, S. I., Seibert, J., \& Zappa, M. (2015). Does model performance improve with complexity? a case study with three hydrological models. Journal of Hydrology, 523, 147-159. doi 10.1016/j.jhydrol.2015.01.044

Papathoma-Köhle, M., Zischg, A., Fuchs, S., Glade, T., \& Keiler, M. (2015). Loss estimation for landslides in mountain areas - an integrated toolbox for vulnerability assessment and damage documentation. Environmental Modelling 83 Software, 63, 156-169. doi $10.1016 /$ j.envsoft.2014.10.003.

Pattison, I., Lane, S. N., Hardy, R. J., \& Reaney, S. M. (2014). The role of tributary relative timing and sequencing in controlling large floods. Water Resources Research, (p. 54445458). doi 10.1002/2013WR014067

Piniewski, M., Voss, F., Bärlund, I., Okruszko, T., \& Kundzewicz, Z. W. (2013). Effect of modelling scale on the assessment of climate change impact on river runoff. Hydrological Sciences Journal, 58, 737-754. doi 10.1080/02626667.2013.778411.

Piras, M., Mascaro, G., Deidda, R., \& Vivoni, E. R. (2016). Impacts of climate change on precipitation and discharge extremes through the use of statistical downscaling approaches in a mediterranean basin. Science of The Total Environment, 543, 952-964. doi $10.1016 /$ j.scitotenv.2015.06.088

Prein, A. F., Langhans, W., Fosser, G., Ferrone, A., Ban, N., Goergen, K., Keller, M., Tlle, M., Gutjahr, O., Feser, F., Brisson, E., Kollet, S., Schmidli, J., van Lipzig, N. P. M., \& Leung, R. (2015). A review on regional convection-permitting climate modeling: Demonstrations, prospects, and challenges, . 53, 2014RG000475. doi 10.1002/2014RG000475

Röthlisberger, V., Zischg, A. P., \& Keiler, M. (2017). Identifying spatial clusters of flood exposure to support decision making in risk management. The Science of the total environment, 598, 593-603. doi 10.1016/j.scitotenv.2017.03.216.

Salathé, E. P., Hamlet, A. F., Mass, C. F., Lee, S.-Y., Stumbaugh, M., \& Steed, R. (2014). Estimates of twenty-first-century flood risk in the pacific northwest based on regional climate model simulations. Journal of Hydrometeorology, 15, 1881-1899. doi $10.1175 / \mathrm{JHM}-\mathrm{D}-13-0137.1$.

Samuels, P. G. (1990). Cross section location in one-dimensional models. In H. R. Ltd. (Ed.), Int. Conf. on River Flood Hydraulics (pp. 339-350). Wallingford, Oxfordshire.

Schröter, K., Kreibich, H., Vogel, K., Riggelsen, C., Scherbaum, F., \& Merz, B. (2014). How useful are complex flood damage models? Water Resources Research, 50, 3378-3395. doi 10.1002/2013WR014396

Semenov, M. A. (2008). Simulation of extreme weather events by a stochastic weather generator. Climate Research, 35, 203-212. doi $10.3354 / \mathrm{cr} 00731$

Skamarock, W. C., Klemp, J. B., Dudhia, J., Gill, D. O., Barker, D. M., Wang, W., \& Powers, J. G. (2008). A description of the advanced research WRF version 3. Technical Report TN475+STR National Center for Atmospheric Research.

Skublics, D., Seibert, S., \& Ehret, U. (2014). Modelling flood retention with hydrological and hydrodynamic models under different boundary conditions - sensitivity analysis on the danube reach from neu-ulm to donauwörth. Hydrologie und Wasserbewirtschaftung, (pp. 178-189). doi 10.5675/HyWa\_2014.

Stucki, P., Dierer, S., Welker, C., Gmez-Navarro, J. J., Raible, C. C., Martius, O., \& Brnnimann, S. (2016). Evaluation of downscaled wind speeds and parameterised gusts for recent and historical windstorms in Switzerland. Tellus A, 68. URL: 

M., Kriaučiuniene, J., Loukas, A., Osuch, M., \& Yücel, I. (2015). Inter-comparison of statistical downscaling methods for projection of extreme precipitation in europe. Hydrology and Earth System Sciences, 19, 1827-1847. doi 10.5194/ hess-19-1827-2015

SVKG (2012). Das Schweizerische Schätzerhandbuch. Aarau.

Teng, J., Vaze, J., Chiew, Francis H. S., Wang, B., \& Perraud, J.-M. (2012). Estimating the relative uncertainties sourced from gcms and hydrological models in modeling climate change impact on runoff. Journal of Hydrometeorology, $13,122-139$. doi $10.1175 / \mathrm{JHM}-\mathrm{D}-11-058.1$

Thieken, A. H., Cammerer, H., Dobler, C., Lammel, J., \& Schöberl, F. (2016). Estimating changes in flood risks and benefits of non-structural adaptation strategies - a case study from tyrol, austria. Mitigation and Adaptation Strategies for Global Change, 21, 343-376. doi 10.1007/s11027-014-9602-3

Tofiq, F. A., \& Guven, A. (2014). Prediction of design flood discharge by statistical downscaling and general circulation models. Journal of Hydrology, (pp. 1145-1153). URL: 517. doi 10.1016/j.jhydrol.2014.06.028

Totschnig, R., Sedlacek, W., \& Fuchs, S. (2011). A quantitative vulnerability function for fluvial sediment transport. Natural Hazards, 58, 681-703. doi 10.1007/s11069-010-9623-5

Vandenberghe, S., Verhoest, N. E. C., Buyse, E., \& de Baets, B. (2010). A stochastic design rainfall generator based on copulas and mass curves. Hydrology and Earth System Sciences, 14, 2429-2442. doi 10.5194/hess-14-2429-2010

Vetsch, D., Siviglia, A., Ehrbar, D., Facchini, M., Gerber, M., Kammerer, S., Peter, S., Vonwiller, L., Volz, C., Farshi, D., Mueller, R., Rousselot, P., Veprek, R., \& Faeh, R. (2016). Basement: Basic simulation environment for computation of environmental flow and natural hazard simulation. URL: www.basement.ethz.ch

Viviroli, D., Mittelbach, H., Gurtz, J., \& Weingartner, R. (2009a). Continuous simulation for flood estimation in ungauged mesoscale catchments of switzerland - part ii: Parameter regionalisation and flood estimation results. Journal of Hydrology, 377, 208-225. doi $10.1016 / \mathrm{j} \cdot \mathrm{jhydrol} .2009 .08 .022$

Viviroli, D., Zappa, M., Gurtz, J., \& Weingartner, R. (2009b). An introduction to the hydrological modelling system prevah and its pre- and post-processing-tools. Environmental Modelling ES Software, 24, 1209-1222. doi:10.1016/j.envsoft.2009. 04.001

Vorogushyn, S., Lindenschmidt, K.-E., Kreibich, H., Apel, H., \& Merz, B. (2012). Analysis of a detention basin impact on dike failure probabilities and flood risk for a channel-dike-floodplain system along the river elbe, germany. Journal of Hydrology, (pp. 120-131). doi $10.1016 / \mathrm{j} \cdot \mathrm{jhydrol.2012.03.006}$

Wang, C., Zhang, L., Lee, S.-K., Wu, L., \& Mechoso, C. R. (2014). A global perspective on CMIP5 climate model biases.

口 Nature Climate Change, 4, 201-205. URL: http://www.nature.com/nclimate/journal/v4/n3/full/nclimate2118.html? foxtrotcallback=true doi $10.1038 /$ nclimate 2118

Wilby, R. L. (2010). Evaluating climate model outputs for hydrological applications. Hydrological Sciences Journal, 55, 1090-1093. doi $10.1080 / 02626667.2010 .513212$

Winsemius, H. C., Aerts, Jeroen C. J. H., van Beek, Ludovicus P. H., Bierkens, Marc F. P., Bouwman, A., Jongman, B., Kwadijk, Jaap C. J., Ligtvoet, W., Lucas, P. L., van Vuuren, Detlef P., \& Ward, P. J. (2015). Global drivers of future river flood risk. Nature Climate Change, 6, 381-385. doi 10.1038/nclimate2893

WMO (2009). Manual on estimation of probable maximum precipitation (pmp).

Xu, Y.-P., Gao, X., Zhu, Q., Zhang, Y., \& Kang, L. (2015). Coupling a regional climate model and a distributed hydrological model to assess future water resources in jinhua river basin, east china. Journal of Hydrologic Engineering, 20 , 04014054. doi $10.1061 /$ (ASCE) HE. 1943-5584.0001007

Zappa, M., Andres, N., Kienzler, P., Näf-Huber, D., Marti, C., \& Oplatka, M. (2015). Crash tests for forward-looking flood 
control in the city of zürich (switzerland). Proceedings of the International Association of Hydrological Sciences, (pp. 235-242). doi 10.5194/piahs-370-235-2015

Zittis, G., Bruggeman, A., Camera, C., Hadjinicolaou, P., \& Lelieveld, J. (2017). The added value of convection permitting 1. simulations of extreme precipitation events over the eastern mediterranean, . 191, 20-33. doi 10.1016/j.atmosres.2017. 03.002 